\title{
Anisotropy of Elastic Properties of Metal-Organic Frameworks and the Breathing Phenomenon
}

\author{
Eugeny V. Alexandrov, ${ }^{1,2^{*}}$ Andrey V. Goltsev, ${ }^{2}$ Roman A. Eremin, ${ }^{1,2}$ Vladislav A. Blatov ${ }^{1,2 *}$
}

\author{
${ }^{1}$ Samara Center for Theoretical Materials Science (SCTMS), Samara University, Moskovskoye \\ shosse 34, Samara 443086, Russian Federation \\ ${ }^{2}$ Samara Center for Theoretical Materials Science (SCTMS), Samara State Technical University, \\ Molodogvardeyskaya street 244, Samara, 443100, Russian Federation
}

Supporting Information 


\section{Section 1. Results of DFT calculations}

Table S1. Composition and underlying topology of 22 metal-organic frameworks

\begin{tabular}{|c|c|c|c|c|c|}
\hline $\begin{array}{l}\text { CSD } \\
\text { Reference } \\
\text { Code }\end{array}$ & Material & Metal & Ligand & $\begin{array}{l}\text { Coord. } \\
\text { number } \\
\text { of } \\
\text { linker }\end{array}$ & $\begin{array}{l}\text { Underlying } \\
\text { net }\end{array}$ \\
\hline WOJJOV & $\mathrm{Al}(\mathrm{OH})(1,4-\mathrm{ndc})$ & $\mathrm{Al}$ & naphthalene-1,4-dicarboxylate & 4 & crb \\
\hline PEYSUJ & CAU-10-Br & $\mathrm{Al}$ & 5-bromoisophthalate & 4 & gis \\
\hline CELZOK & CAU-10-CH3 & $\mathrm{Al}$ & 5-methylisophthalate & 4 & gis \\
\hline CELZUQ & CAU-10-H & $\mathrm{Al}$ & isophthalate & 4 & gis \\
\hline CELZIE & CAU-10-OCH3 & $\mathrm{Al}$ & 5-methoxyisophthalate & 4 & gis \\
\hline ZESZEE & CAU-8 & $\mathrm{Al}$ & 4,4'-carbonyldibenzoate & 4 & $4 / 5 / t 1$ \\
\hline HAFVUH & CPF-1 & $\mathrm{Mg}$ & biphenyl-3,3',5,5'-tetracarboxylate & 8 & cda \\
\hline XOCROY & MIL-116(Al) & $\mathrm{Al}$ & 1,4-dicarboxybenzene-2,3,5,6-tetracarboxylate & 8 & mog \\
\hline GUKVEO & MIL-118(Al) & $\mathrm{Al}$ & benzene-1,2,4,5-tetracarboxylate & 8 & $\operatorname{mog}$ \\
\hline RAWZIA & MIL-121(Al) & $\mathrm{Al}$ & dihydrogenpyromellitate & 4 & dia \\
\hline NUFYAP & MIL-122(Al) & $\mathrm{Al}$ & 1,4,5,8-naphthalenetetracarboxylate & 8 & mog \\
\hline NUFYET & MIL-122(Ga) & $\mathrm{Ga}$ & 1,4,5,8-naphthalenetetracarboxylate & 8 & mog \\
\hline SABVUN & MIL-53(Al) & $\mathrm{Al}$ & benzene-1,4-dicarboxylate & 4 & dia \\
\hline POJTOY & MIL-53(Fe) & $\mathrm{Fe}$ & benzene-1,4-dicarboxylate & 4 & dia \\
\hline LOQLIN01 & MIL-53(Ga) & $\mathrm{Ga}$ & benzene-1,4-dicarboxylate & 4 & dia \\
\hline ASOHUL & MIL-53(V) & $\mathrm{V}$ & benzene-1,4-dicarboxylate & 4 & dia \\
\hline GUXQAR & MIL-60(V) & $\mathrm{V}$ & 1,2,4,5-benzenetetracarboxylate & 8 & mog \\
\hline GUXQEV & MIL-61(V) & V & benzene-2,4,5-tricarboxylato-1-carboxylate & 4 & dia \\
\hline XADCOW & MIL-68(Fe) & $\mathrm{Fe}$ & benzene-1,4-dicarboxylate & 4 & bik \\
\hline ATOTIM & MIL-68(V) & $\mathrm{V}$ & benzene-1,4-dicarboxylate & 4 & bik \\
\hline EXEQII & NOTT-400 & Sc & biphenyl-3,3',5,5'-tetracarboxylate & 8 & cda \\
\hline EXEQEE & NOTT-401 & $\mathrm{Sc}$ & thiophene-2,5-dicarboxylate & 4 & gis \\
\hline
\end{tabular}


Table S2. Monkhorst-Pack (MP) k-point grids used in the calculations

\begin{tabular}{|c|c|c|c|c|c|c|c|}
\hline \multirow{2}{*}{$\begin{array}{l}\text { CSD Reference } \\
\text { Code }\end{array}$} & \multicolumn{5}{|c|}{ Unit cell parameters (from experiment) } & \multirow{2}{*}{$\begin{array}{l}\text { MP k- } \\
\text { points }\end{array}$} & \multirow{2}{*}{$\begin{array}{l}\text { Irreduc. } \\
\text { k-points }\end{array}$} \\
\hline & Sp. Gr. & $a, \AA$ & $b, \AA$ & $c, \AA$ & angle, ${ }^{\circ}$ & & \\
\hline MIL-60(V) & $\mathrm{P}-1$ & 6.3758 & 6.8840 & 9.0254 & $\begin{array}{l}\alpha=69.01 \\
\beta=85.20 \\
\gamma=79.45\end{array}$ & $4 \times 4 \times 3$ & 26 \\
\hline MIL-118(Al) & Pbam & 11.3322 & 6.6189 & 8.7217 & & $2 \times 4 \times 3$ & 12 \\
\hline MIL-122(Al) & $\mathrm{P} 2{ }_{1} / \mathrm{c}$ & 9.5182 & 10.0695 & 6.6464 & $\beta=91.26$ & $3 \times 3 \times 4$ & 14 \\
\hline MIL-122(Ga) & $\mathrm{P} 2{ }_{1} / \mathrm{c}$ & 9.6501 & 10.0585 & 6.7507 & $\beta=92.48$ & $2 \times 2 \times 2$ & 8 \\
\hline MIL-53(Al) & Imma & 6.6085 & 16.6750 & 12.8130 & & $4 \times 2 \times 2$ & 12 \\
\hline MIL-53(Fe) & $\mathrm{C} 2 / \mathrm{c}$ & 21.2693 & 6.7589 & 6.8838 & $\beta=114.63$ & $2 \times 2 \times 4$ & 12 \\
\hline MIL-53(Ga) & $\mathrm{C} 2 / \mathrm{c}$ & 19.8330 & 6.8556 & 6.7143 & $\beta=103.88$ & $2 \times 3 \times 5$ & 16 \\
\hline MIL-53(V) & Pnma & 17.6956 & 6.8745 & 11.9303 & & $2 \times 4 \times 2$ & 12 \\
\hline MIL-121(Al) & $\mathrm{C} 2 / \mathrm{c}$ & 17.5448 & 13.5781 & 6.6642 & $\beta=113.20$ & $1 \times 2 \times 3$ & 4 \\
\hline MIL-61(V) & Pnma & 14.8860 & 6.9164 & 10.6669 & & $2 \times 4 \times 2$ & 8 \\
\hline MIL-116(Al) & $\mathrm{C} 2 / \mathrm{c}$ & 11.7300 & 6.7420 & 17.5780 & $\beta=90.00$ & $2 \times 4 \times 2$ & 12 \\
\hline NOTT-400 & $\mathrm{I} 4{ }_{1} 22$ & 15.3470 & & 12.3845 & & $2 \times 2 \times 2$ & 6 \\
\hline CPF-1 & $\mathrm{I} 4_{1} 22$ & 15.2927 & & 12.3010 & & $3 \times 3 \times 4$ & 9 \\
\hline CAU-10-CH3 & I4_/amd & 21.4917 & & 10.1810 & & $1 \times 1 \times 2$ & 2 \\
\hline $\mathrm{Al}(\mathrm{OH})(1,4-\mathrm{ndc})$ & $\mathrm{P} 4 / \mathrm{nmm}$ & 21.1012 & & 6.6095 & & $1 \times 1 \times 4$ & 3 \\
\hline MIL-68(Fe) & $\mathrm{Cmcm}$ & 21.3011 & 36.8730 & 6.8883 & & $2 \times 1 \times 5$ & 6 \\
\hline MIL-68(Ga) & $\mathrm{Cmcm}$ & 21.1760 & 36.7030 & 6.7423 & & $1 \times 1 \times 3$ & 2 \\
\hline MIL-68(V) & $\mathrm{Cmcm}$ & 21.2105 & 36.7210 & 6.8606 & & $2 \times 1 \times 5$ & 6 \\
\hline NOTT-401 & I41/amd & 22.6050 & & 12.4740 & & $1 \times 1 \times 2$ & 2 \\
\hline CAU-10-Br & I4/amd & 21.5064 & & 10.1648 & & $1 \times 1 \times 2$ & 2 \\
\hline CAU-10-H & $\mathrm{I} 4_{1}$ & 21.5470 & & 10.3780 & & $1 \times 1 \times 3$ & 2 \\
\hline CAU-10-OCH3 & $\mathrm{I} 4_{1} / \mathrm{a}$ & 21.3609 & & 10.5698 & & $1 \times 1 \times 2$ & 2 \\
\hline CAU-8 & $\mathrm{I} 4_{1} / \mathrm{a}$ & 13.0625 & & 52.5650 & & $3 \times 3 \times 1$ & 3 \\
\hline
\end{tabular}


Table S3. Optimized unit cell parameters of the metal-organic frameworks

\begin{tabular}{|c|c|c|c|c|c|c|c|c|}
\hline \multirow{2}{*}{$\begin{array}{l}\text { CSD } \\
\text { Reference } \\
\text { Code }\end{array}$} & \multicolumn{4}{|c|}{ unit cell (from experiment) } & \multicolumn{4}{|c|}{ unit cell (calculated) } \\
\hline & $a, \AA$ & $b, \AA$ & $c, \AA$ & angle, ${ }^{\circ}$ & $a, \AA$ & $b, \AA$ & $c, \AA$ & angle, ${ }^{\circ}$ \\
\hline MIL-60(V) & 6.3758 & 6.8840 & 9.0254 & $\begin{array}{l}\alpha=69.01 \\
\beta=85.20 \\
\gamma=79.45\end{array}$ & 6.4273 & 6.9160 & 9.1251 & $\begin{array}{l}67.908 \\
85.999 \\
79.133\end{array}$ \\
\hline MIL-118(Al) & 11.3322 & 6.6189 & 8.7217 & & 11.8675 & 6.7144 & 8.7046 & \\
\hline MIL-122(Al) & 9.5182 & 10.0695 & 6.6464 & $\beta=91.26$ & 9.5622 & 10.3939 & 6.7209 & 92.091 \\
\hline MIL-122(Ga) & 9.6501 & 10.0585 & 6.7507 & $\beta=92.48$ & 9.7120 & 10.4142 & 6.8430 & 92.485 \\
\hline MIL-53(Al) & 6.6085 & 16.6750 & 12.8130 & & 6.7418 & 16.8676 & 12.9886 & \\
\hline MIL-53(Fe) & 21.2693 & 6.7589 & 6.8838 & $\beta=114.63$ & 17.4049 & 13.9556 & 6.6797 & 112.53 \\
\hline MIL-53(Ga) & 19.8330 & 6.8556 & 6.7143 & $\beta=103.88$ & 17.9085 & 13.9611 & 6.8269 & 112.54 \\
\hline MIL-53(V) & 17.6956 & 6.8745 & 11.9303 & & 17.6781 & 6.9851 & 12.2450 & \\
\hline MIL-121(Al) & 17.5448 & 13.5781 & 6.6642 & $\beta=113.20$ & 17.6321 & 13.7175 & 6.7807 & 112.74 \\
\hline MIL-61(V) & 14.8860 & 6.9164 & 10.6669 & & 14.9616 & 7.1006 & 10.7551 & \\
\hline MIL-116(Al) & 11.7300 & 6.7420 & 17.5780 & $\beta=90$ & 11.6225 & 6.7896 & 17.7681 & 90.462 \\
\hline NOTT-400 & 15.3470 & & 12.3845 & & 15.5251 & & 12.5593 & \\
\hline CPF-1 & 15.2927 & & 12.3010 & & 15.3144 & & 12.6133 & \\
\hline $\begin{array}{l}\text { CAU-10- } \\
\mathrm{CH} 3\end{array}$ & 21.4917 & & 10.1810 & & 21.7670 & & 10.6609 & \\
\hline $\begin{array}{l}\mathrm{Al}(\mathrm{OH})(1,4- \\
\mathrm{ndc})\end{array}$ & 21.1012 & & 6.6095 & & 21.5513 & & 6.7450 & \\
\hline MIL-68(Fe) & 21.3011 & 36.8730 & 6.8883 & & 21.1638 & 36.2584 & 6.6898 & \\
\hline MIL-68(Ga) & 21.1760 & 36.7030 & 6.7423 & & 21.5627 & 36.9155 & 6.8836 & \\
\hline MIL-68(V) & 21.2105 & 36.7210 & 6.8606 & & 21.5124 & 36.8005 & 6.9975 & \\
\hline NOTT-401 & 22.6050 & & 12.4740 & & 22.8236 & & 12.8221 & \\
\hline CAU-10-Br & 21.5064 & & 10.1648 & & 21.7945 & & 10.6343 & \\
\hline CAU-10-H & 21.5470 & & 10.3780 & & 21.7945 & & 10.6343 & \\
\hline $\begin{array}{l}\text { CAU-10- } \\
\mathrm{OCH} 3\end{array}$ & 21.3609 & & 10.5698 & & 21.7806 & & 10.7254 & \\
\hline CAU-8 & 13.0625 & & 52.5650 & & 13.3068 & & 53.1281 & \\
\hline
\end{tabular}

Table S4. Elastic constants (GPa) in the Voigt notation for MOFs in orthorhombic crystal system

\begin{tabular}{|l|l|l|l|l|l|l|l|l|l|l|}
\hline $\begin{array}{l}\text { CSD } \\
\text { Reference } \\
\text { Code }\end{array}$ & $\begin{array}{l}\text { Cutoff } \\
\text { energy, } \\
\text { eV }\end{array}$ & $\mathrm{C}_{11}$ & $\mathrm{C}_{22}$ & $\mathrm{C}_{33}$ & $\mathrm{C}_{44}$ & $\mathrm{C}_{55}$ & $\mathrm{C}_{66}$ & $\mathrm{C}_{12}$ & $\mathrm{C}_{13}$ & $\mathrm{C}_{23}$ \\
\hline MIL-118(Al) & 900 & 22.94 & 113.84 & 172.23 & 9.12 & 42.31 & 5.93 & 9.77 & 37.03 & 29.48 \\
\hline MIL-53(V) & 650 & 97.58 & 43.88 & 18.59 & 5.27 & 24.34 & 9.73 & 16.57 & 40.92 & 7.06 \\
\hline MIL-53(Al) & 850 & 60.17 & 83.23 & 25.26 & 32.24 & 7.31 & 8.81 & 17.50 & 10.05 & 45.08 \\
\hline MIL-68(Fe) & 850 & 65.32 & 50.09 & 43.66 & 6.54 & 7.48 & 9.01 & 20.81 & 8.37 & 6.33 \\
\hline MIL-68(V) & 650 & 51.47 & 39.98 & 35.82 & 5.79 & 4.16 & 5.67 & 26.56 & 8.38 & 9.49 \\
\hline MIL-61(V) & 900 & 83.72 & 61.87 & 71.65 & 4.18 & 33.98 & 7.25 & 14.55 & 47.16 & 13.09 \\
\hline
\end{tabular}


Table S5. Elastic constants (GPa) in the Voigt notation for MOFs in tetragonal crystal system

\begin{tabular}{|l|l|l|l|l|l|l|l|l|}
\hline CSD RefCode & $\begin{array}{l}\text { Cutoff } \\
\text { energy, eV }\end{array}$ & $\mathrm{C}_{11}$ & $\mathrm{C}_{33}$ & $\mathrm{C}_{44}$ & $\mathrm{C}_{66}$ & $\mathrm{C}_{12}$ & $\mathrm{C}_{13}$ & $\mathrm{C}_{16}$ \\
\hline NOTT-400 & 650 & 36.67 & 97.61 & 16.15 & 15.51 & 35.16 & 20.70 & 0 \\
\hline CPF-1 & 850 & 37.76 & 85.76 & 11.73 & 12.19 & 34.82 & 21.99 & 0 \\
\hline Al(OH)(1,4-ndc) & 850 & 84.79 & 54.99 & 9.35 & 2.40 & 14.92 & 15.66 & 0 \\
\hline CAU-10-OCH3 & 1000 & 83.69 & 3.36 & 10.80 & 6.61 & 10.60 & 4.41 & 0.87 \\
\hline NOTT-401 & 800 & 62.98 & 7.00 & 6.13 & 1.52 & 10.12 & 7.39 & 0 \\
\hline CAU-10-CH3 & 600 & 82.08 & 5.50 & 7.91 & 5.01 & 9.85 & 4.15 & 0 \\
\hline CAU-8 & 600 & 12.67 & 24.48 & 3.26 & 0.69 & -0.59 & 1.79 & 0.41 \\
\hline CAU-10-Br & 900 & 84.18 & 12.09 & 12.46 & 5.58 & 9.64 & 6.99 & -0.14 \\
\hline CAU-10-H & 900 & 78.58 & 11.09 & 8.42 & 2.70 & 6.43 & 3.29 & -0.09 \\
\hline
\end{tabular}

Table S6. Elastic constants (GPa) in the Voigt notation for MOFs in monoclinic crystal system

\begin{tabular}{|l|l|l|l|l|l|l|l|l|l|l|l|l|l|l|}
\hline $\begin{array}{c}\text { CSD } \\
\text { RefCode }\end{array}$ & $\begin{array}{c}\text { Cutoff } \\
\text { energy, } \\
\text { eV }\end{array}$ & $\mathrm{C}_{11}$ & $\mathrm{C}_{22}$ & $\mathrm{C}_{33}$ & $\mathrm{C}_{44}$ & $\mathrm{C}_{55}$ & $\mathrm{C}_{66}$ & $\mathrm{C}_{12}$ & $\mathrm{C}_{13}$ & $\mathrm{C}_{23}$ & $\mathrm{C}_{15}$ & $\mathrm{C}_{25}$ & $\mathrm{C}_{35}$ & $\mathrm{C}_{46}$ \\
\hline MIL-122(Al) & 900 & 252.28 & 32.63 & 115.75 & 28.51 & 20.90 & 30.57 & 34.56 & 38.89 & 12.17 & -16.95 & -1.91 & -9.61 & -1.26 \\
\hline MIL-122(Ga) & 850 & 220.74 & 29.46 & 96.25 & 24.04 & 28.57 & 30.45 & 30.86 & 35.92 & 9.93 & -18.21 & -3.97 & -6.76 & -2.04 \\
\hline MIL-121(Al) & 800 & 68.63 & 47.80 & 62.02 & 15.96 & 14.97 & 41.20 & 39.48 & 11.55 & 17.22 & -1.87 & 6.37 & 4.14 & 1.71 \\
\hline MIL-116(Al) & 900 & 42.93 & 118.67 & 229.44 & 18.32 & 72.32 & 7.84 & 23.93 & 57.70 & 44.60 & -1.29 & -0.82 & -2.17 & 2.21 \\
\hline MIL-53(Ga) & 600 & 49.17 & 23.17 & 33.27 & 5.60 & 8.34 & 31.97 & 33.05 & 5.57 & 3.69 & 0.89 & 1.70 & 0.16 & 0.73 \\
\hline MIL-53(Fe) & 750 & 71.81 & 39.22 & 53.74 & 8.43 & 11.59 & 45.26 & 51.38 & 14.28 & 11.55 & 1.11 & -0.74 & 1.67 & -1.33 \\
\hline
\end{tabular}

Table S7. Elastic constants (GPa) in the Voigt notation for MIL-60 in triclinic crystal system P-1 $($ cutoff energy $=650 \mathrm{eV}$ )

\begin{tabular}{|l|l|l|l|l|l|l|l|l|l|l|}
\hline $\mathrm{C}_{11}$ & $\mathrm{C}_{12}$ & $\mathrm{C}_{13}$ & $\mathrm{C}_{14}$ & $\mathrm{C}_{15}$ & $\mathrm{C}_{16}$ & $\mathrm{C}_{22}$ & $\mathrm{C}_{23}$ & $\mathrm{C}_{24}$ & $\mathrm{C}_{25}$ & $\mathrm{C}_{26}$ \\
\hline 57.55 & 23.03 & 51.32 & -12.45 & 7.71 & 20.17 & 74.19 & 29.91 & 1.34 & -8.22 & 16.79 \\
\hline $\mathrm{C}_{33}$ & $\mathrm{C}_{34}$ & $\mathrm{C}_{35}$ & $\mathrm{C}_{36}$ & $\mathrm{C}_{44}$ & $\mathrm{C}_{45}$ & $\mathrm{C}_{46}$ & $\mathrm{C}_{55}$ & $\mathrm{C}_{56}$ & \multicolumn{2}{c}{$\mathrm{C}_{66}$} \\
\hline 105.55 & -21.62 & 18.10 & 11.78 & 28.78 & 9.61 & -7.64 & 32.91 & 1.34 & 25.08 \\
\hline
\end{tabular}


Table S8. Maximum and minimum values of Young's modulus $(E)$, shear modulus $(G)$, linear compressibility $(\beta)$, and Poisson's ratio $(v)$ for 22 rod-MOFs

\begin{tabular}{|c|c|c|c|c|c|c|c|c|c|c|c|}
\hline \multirow[b]{2}{*}{ MOF } & \multicolumn{4}{|l|}{$E$, Gpa } & \multicolumn{2}{|c|}{$G$, Gpa } & \multirow[b]{2}{*}{$\begin{array}{l}\max / \min \\
\left(A_{G}\right)\end{array}$} & \multicolumn{2}{|c|}{$\beta$, TPa-1 } & \multicolumn{2}{|l|}{$v$} \\
\hline & $\begin{array}{l}\text { Average } \\
\text { by Voigt }\end{array}$ & $\min$ & $\max$ & $\begin{array}{l}\max / \min \\
\left(A_{E}\right)\end{array}$ & $\min$ & $\max$ & & $\min$ & $\max$ & $\min$ & $\max$ \\
\hline $\mathrm{Al}(\mathrm{OH})(1,4-\mathrm{ndc})$ & 41.93 & 9.12 & 78.97 & 8.66 & 2.40 & 34.94 & 14.56 & 7.88 & 13.70 & -0.08 & 0.91 \\
\hline CAU-10-Br & 40.77 & 11.05 & 79.75 & 7.22 & 5.58 & 37.27 & 6.68 & 4.92 & 77.02 & -0.23 & 0.77 \\
\hline CAU-10-CH3 & 35.44 & 5.13 & 78.38 & 15.29 & 3.72 & 36.12 & 9.70 & 2.87 & 177.49 & -0.33 & 0.79 \\
\hline CAU-10-H & 35.05 & 10.14 & 77.22 & 7.62 & 2.70 & 36.08 & 13.36 & 8.47 & 85.15 & -0.21 & 0.88 \\
\hline CAU-10-OCH3 & 38.52 & 2.95 & 77.63 & 26.34 & 2.41 & 36.57 & 15.17 & -3.78 & 307.54 & -0.98 & 0.73 \\
\hline CAU-8 & 10.99 & 2.38 & 23.95 & 10.06 & 0.66 & 7.46 & 11.28 & 29.38 & 78.43 & -0.24 & 0.91 \\
\hline CPF-1 & 33.86 & 5.61 & 72.44 & 12.91 & 1.47 & 19.67 & 13.38 & 5.44 & 12.13 & -0.52 & 1.32 \\
\hline MIL-116(Al) & 95.43 & 22.11 & 194.84 & 8.81 & 7.39 & 72.29 & 9.78 & -2.64 & 24.33 & -0.37 & 1.28 \\
\hline MIL-118(Al) & 68.88 & 14.33 & 134.26 & 9.37 & 5.93 & 42.31 & 7.13 & -6.19 & 51.03 & -0.41 & 1.56 \\
\hline MIL-121(Al) & 54.10 & 20.19 & 87.51 & 4.34 & 6.32 & 41.32 & 6.54 & 1.91 & 14.57 & -0.16 & 0.91 \\
\hline MIL-122(Al) & 92.96 & 27.43 & 212.14 & 7.73 & 15.49 & 61.52 & 3.97 & -1.48 & 29.34 & -0.16 & 0.98 \\
\hline MIL-122(Ga) & 85.94 & 24.82 & 184.97 & 7.45 & 16.50 & 50.80 & 3.08 & -1.77 & 33.04 & -0.11 & 0.98 \\
\hline MIL-53(Al) & 41.80 & 0.84 & 80.29 & 95.87 & 0.35 & 32.24 & 91.65 & -281.06 & 537.79 & -2.42 & 3.10 \\
\hline MIL-53(Fe) & 48.13 & 2.21 & 96.52 & 43.70 & 0.74 & 45.31 & 61.28 & -72.88 & 116.97 & -1.06 & 2.06 \\
\hline MIL-53(Ga) & 33.19 & 0.81 & 67.18 & 83.01 & 0.29 & 31.99 & 111.77 & -260.28 & 410.16 & -1.96 & 2.87 \\
\hline MIL-53(V) & 37.21 & 1.43 & 71.50 & 50.00 & 0.70 & 24.34 & 34.77 & -162.62 & 404.48 & -1.17 & 2.79 \\
\hline MIL-60(V) & 66.87 & 13.22 & 116.80 & 8.84 & 4.59 & 42.85 & 9.34 & -3.09 & 33.29 & -0.36 & 1.27 \\
\hline MIL-61(V) & 48.38 & 14.54 & 86.66 & 5.96 & 4.18 & 33.98 & 8.13 & 5.00 & 13.24 & -0.01 & 0.81 \\
\hline MIL-68(Fe) & 33.00 & 19.91 & 55.91 & 2.81 & 6.54 & 21.58 & 3.30 & 8.36 & 19.26 & 0.08 & 0.57 \\
\hline MIL-68(V) & 23.16 & 13.50 & 33.70 & 2.50 & 4.16 & 15.81 & 3.80 & 8.56 & 22.19 & 0.06 & 0.72 \\
\hline NOTT-400 & 41.48 & 2.95 & 85.68 & 29.05 & 0.76 & 23.56 & 31.20 & 4.94 & 12.50 & -1.50 & 2.26 \\
\hline NOTT-401 & 25.68 & 5.51 & 55.08 & 10.00 & 1.52 & 26.43 & 17.39 & -0.97 & 144.90 & -0.32 & 0.93 \\
\hline
\end{tabular}


Table S9. Eigenvalues of the stiffness matrix (GPa) for 22 rod-MOFs

\begin{tabular}{|l|l|l|l|l|l|l|}
\hline MOF & $\lambda_{1}$ & $\lambda_{2}$ & $\lambda_{3}$ & $\lambda_{4}$ & $\lambda_{5}$ & $\lambda_{6}$ \\
\hline Al(OH)(1,4-ndc) & 2.40 & 9.35 & 9.35 & 45.88 & 69.87 & 108.82 \\
\hline CAU-10-Br & 5.58 & 10.91 & 12.46 & 12.46 & 74.54 & 95.00 \\
\hline CAU-10-CH3 & 5.01 & 5.10 & 7.91 & 7.91 & 72.23 & 92.33 \\
\hline CAU-10-H & 2.70 & 8.42 & 8.42 & 10.80 & 72.15 & 85.30 \\
\hline CAU-10-OCH3 & 2.93 & 6.59 & 10.80 & 10.80 & 73.11 & 94.72 \\
\hline CAU-8 & 0.66 & 3.26 & 3.26 & 11.58 & 13.29 & 24.98 \\
\hline CPF-1 & 2.94 & 11.73 & 11.73 & 12.19 & 47.38 & 110.96 \\
\hline MIL-116(Al) & 7.39 & 18.77 & 25.10 & 72.29 & 103.08 & 262.90 \\
\hline MIL-118(Al) & 5.93 & 9.12 & 14.18 & 42.31 & 101.83 & 193.00 \\
\hline MIL-121(Al) & 9.79 & 15.85 & 20.97 & 41.32 & 54.87 & 107.79 \\
\hline MIL-122(Al) & 19.01 & 27.04 & 27.91 & 31.17 & 105.82 & 269.68 \\
\hline MIL-122(Ga) & 23.45 & 24.04 & 26.94 & 31.04 & 86.72 & 237.31 \\
\hline MIL-53(Al) & 0.65 & 7.31 & 8.81 & 32.24 & 52.78 & 115.23 \\
\hline MIL-53(Fe) & 1.43 & 8.38 & 11.69 & 45.31 & 48.31 & 114.93 \\
\hline MIL-53(Ga) & 0.55 & 5.58 & 8.40 & 31.99 & 32.14 & 72.86 \\
\hline MIL-53(V) & 1.21 & 5.27 & 9.73 & 24.34 & 39.58 & 119.26 \\
\hline MIL-60(V) & 5.60 & 14.88 & 31.06 & 40.19 & 66.62 & 165.72 \\
\hline MIL-61(V) & 4.18 & 7.25 & 30.14 & 33.98 & 56.31 & 130.79 \\
\hline MIL-68(Fe) & 6.54 & 7.48 & 9.01 & 35.52 & 40.87 & 82.68 \\
\hline MIL-68(V) & 4.16 & 5.67 & 5.79 & 18.24 & 32.31 & 76.72 \\
\hline NOTT-400 & 1.51 & 15.51 & 16.15 & 16.15 & 52.73 & 116.71 \\
\hline NOTT-401 & 1.52 & 5.39 & 6.13 & 6.13 & 52.86 & 74.71 \\
\hline
\end{tabular}




\section{Section 2. Detailed description of the structural features of the 22 MOFs}

The mechanical properties for 22 rod-MOFs are grouped below according to their underlying topologies (see Section 3).

The MIL-53 family features the topological motif dia and wine-rack 2D pattern for connection of rods by terephthalate ligands oriented parallel to the rods in MIL-53(V) and MIL-53(Al) or with an angle of $11.9^{\circ}$ in MIL-53(Fe) or $13.8^{\circ}$ in MIL-53(Ga) (Fig. S1). The frameworks of the MIL-53 family with central atoms Al [1], Fe [2], Ga [3], V [4-6] have different symmetry of orthorhombic (Imma for $\mathrm{Al}$, Pnma for $\mathrm{V})$ and monoclinic $(C 2 / c$ for $\mathrm{Fe}$ and $\mathrm{Ga}$ ) systems due to slight shift of the rods along each other in the latter case. The series demonstrates variation of the cell volume up to $50 \%$ accompanying by significant NLC in the direction of the short diagonal of the lozenge-shaped channels. There are strong relations between central atom type and mechanical properties of the frameworks, as well as between the space-group symmetry and the shape of elastic tensor.

In isoreticular MIL-61 (Fig. S2) and MIL-121 (Fig. S3), pyromellitic acid is bonded to rods by two of the four carboxylate groups in the 1,5 and 1,4 positions of the benzene ring, respectively. In MIL-61 of an orthorhombic symmetry Pnma, the plane of the benzene ring of the ligands is orthogonal to the rods. In monoclinic $(C 2 / c)$ MIL-121, the angle between benzene ring and rod is 37.2 $2^{\circ}$ Two free carboxylic groups of the pyromellitic acid in MIL-61 and MIL-121 participate in $\mathrm{H}$-bonds reinforcing the framework. The H-bonds run along the rods and short diagonal of the rhombic channels in MIL-121. In MIL-61, the 2D H-bonded network of ligands is orthogonal to the rods. The COOH-functionalized frameworks, MIL-121(Al) [7] and MIL-61(V) [8], have not shown any significant structural transformations. 

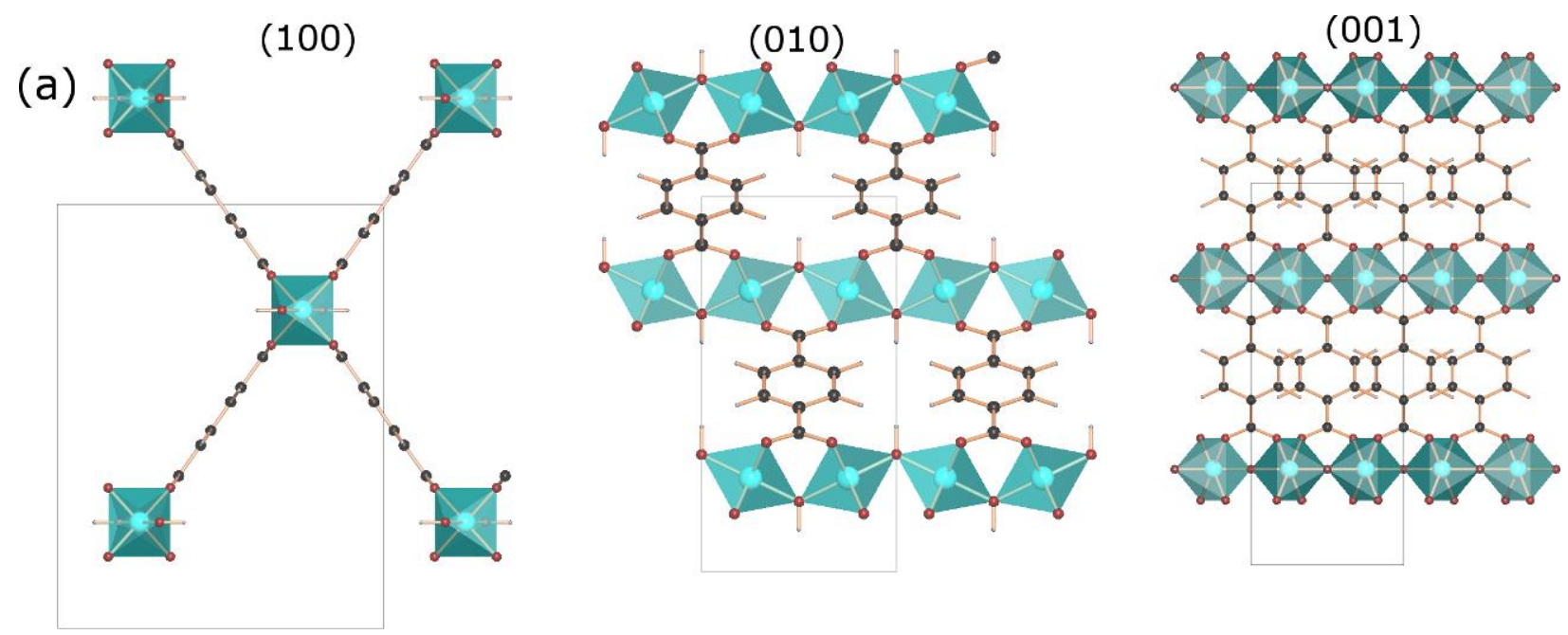

(b)
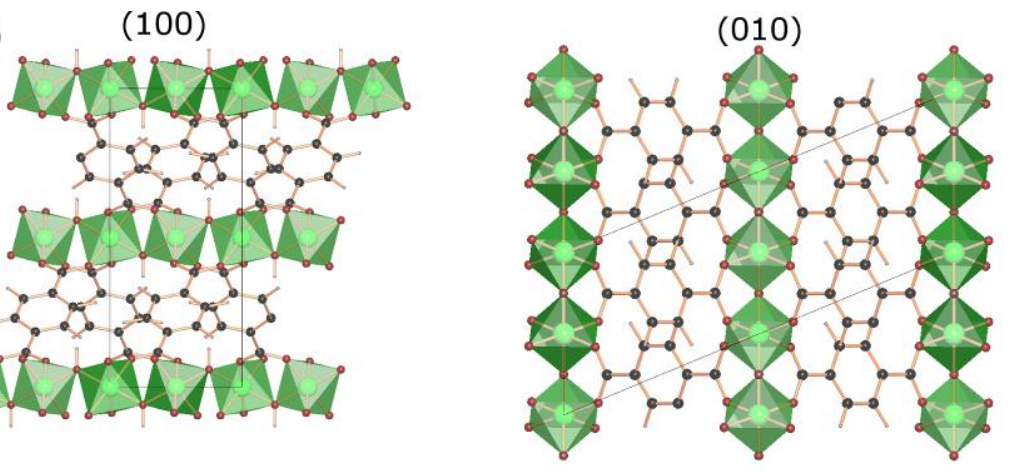

(c)

(100)
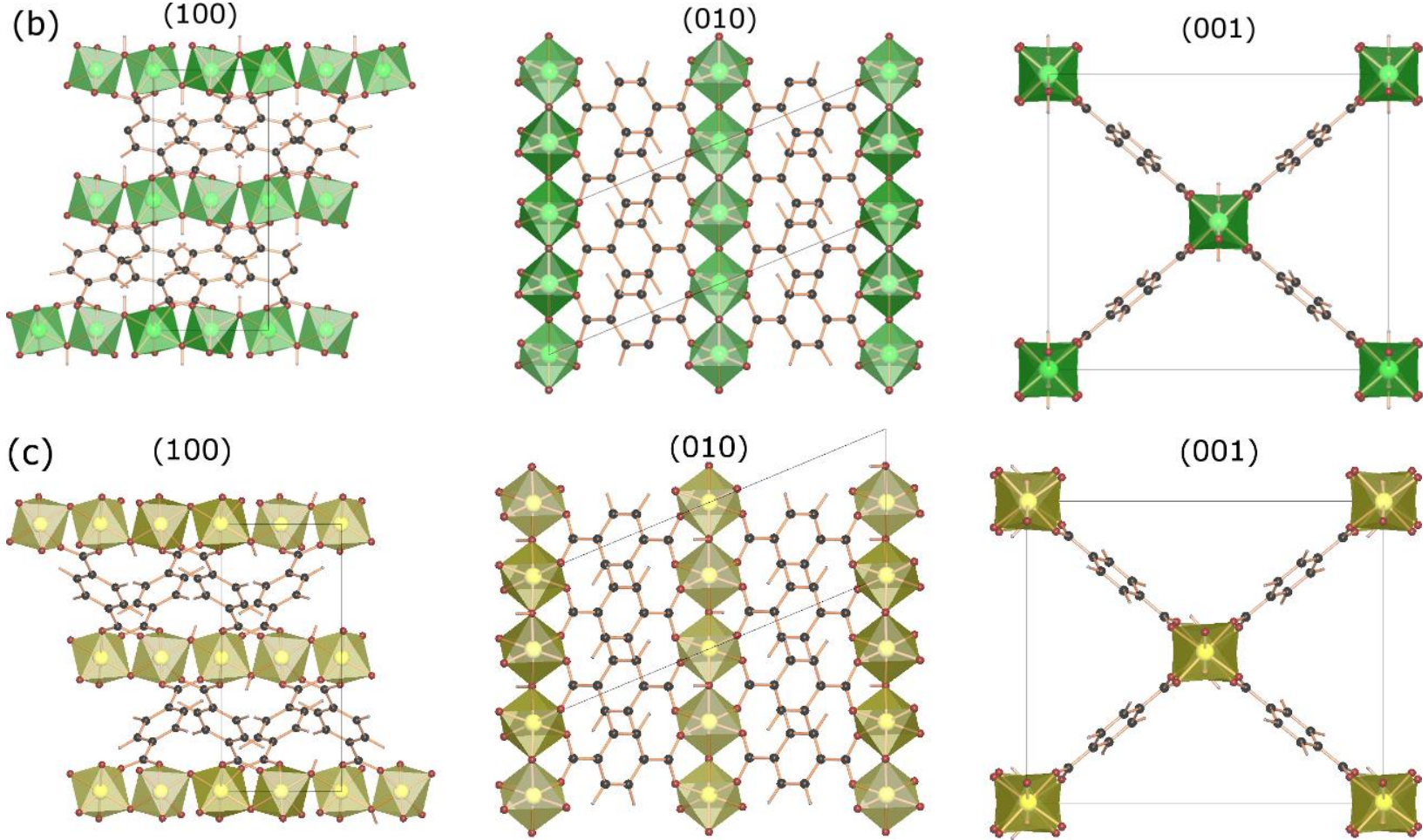

(d)
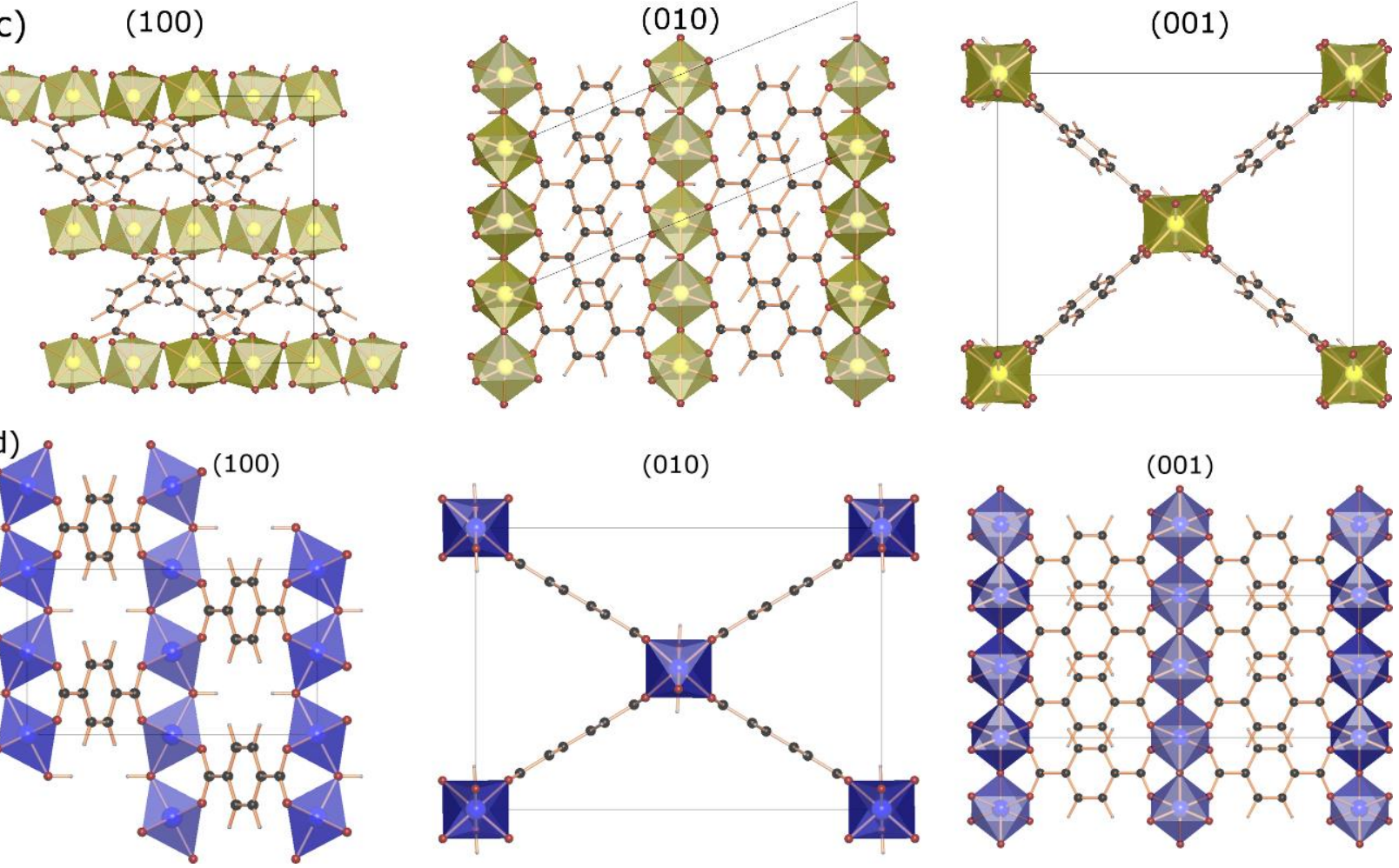

Figure S1. Crystallographic projections (100), (010), (001) of the crystal structures of (a) MIL53(Al) (SABVUN), (b) MIL-53(Fe) (POJTOY), (c) MIL-53(Ga) (LOQLIN01), and (d) MIL53(V) (ASOHUL). 

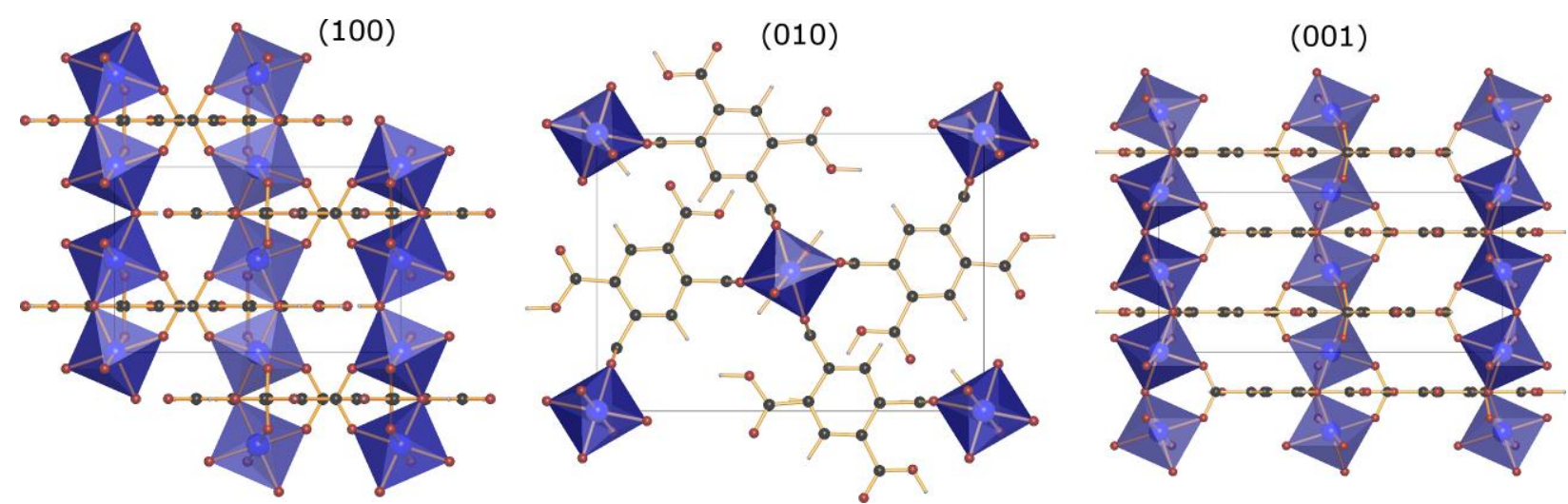

Figure S2. Crystallographic projections (100), (010), (001) of the crystal structures of MIL-61 (GUXQEV).
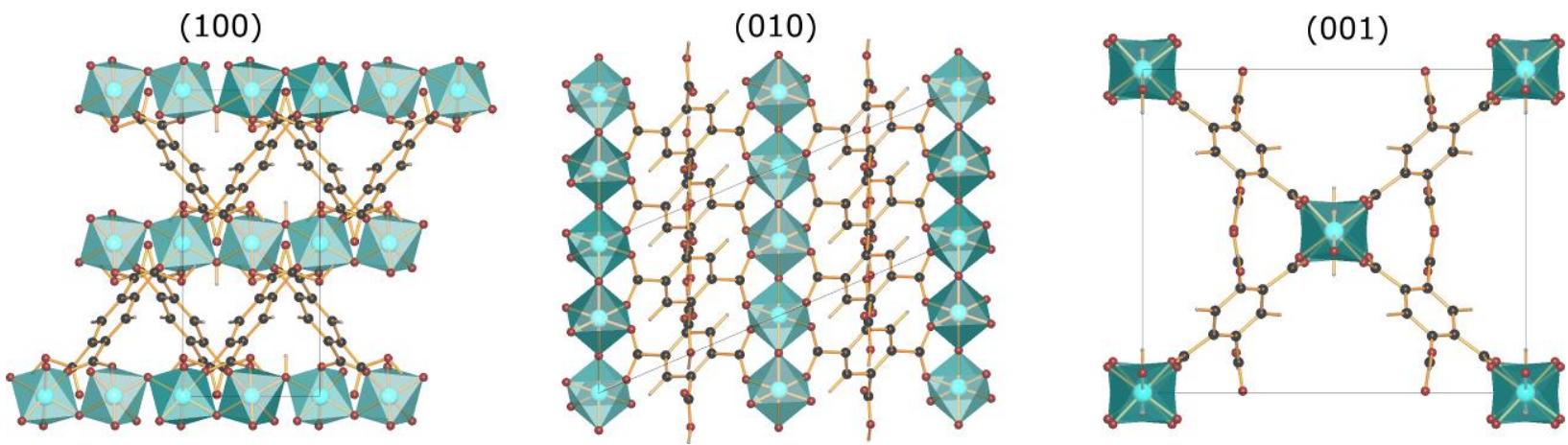

Figure S3. Crystallographic projections (100), (010), (001) of the crystal structures of MIL-121 (RAWZIA).

The series of MIL-68 frameworks (Fig. S4) with central atoms Fe [9] and V [10] is isomeric to the MIL-53 family. The MIL-68 features the bik topology of the underlying net and orthorhombic symmetry $\mathrm{Cmcm}$. The straight rods are periodic in direction [001]. Flat ligands lie in three distinct planes (010), (110), (1-10), forming a Kagome pattern in the (001) projection. The MIL-68 materials are well known by minor flexibility upon adsorption despite the porosity, which is almost the same as in large pores form of MIL-53 (40\% of the unit cell volume) [1113]. The bik underlying net in the maximal-symmetry embedding has space group $\mathrm{Cmcm}$, which is the space group of the three original MOF structures. Despite the trigonal symmetry of the Kagome pattern the space group of MIL-68 does not contain any 3-fold axis. This is due to different connection between rods along directions [010] and [110] or [-110] (Fig. Ошибка! Закладка не определена. and 3). 
(a)
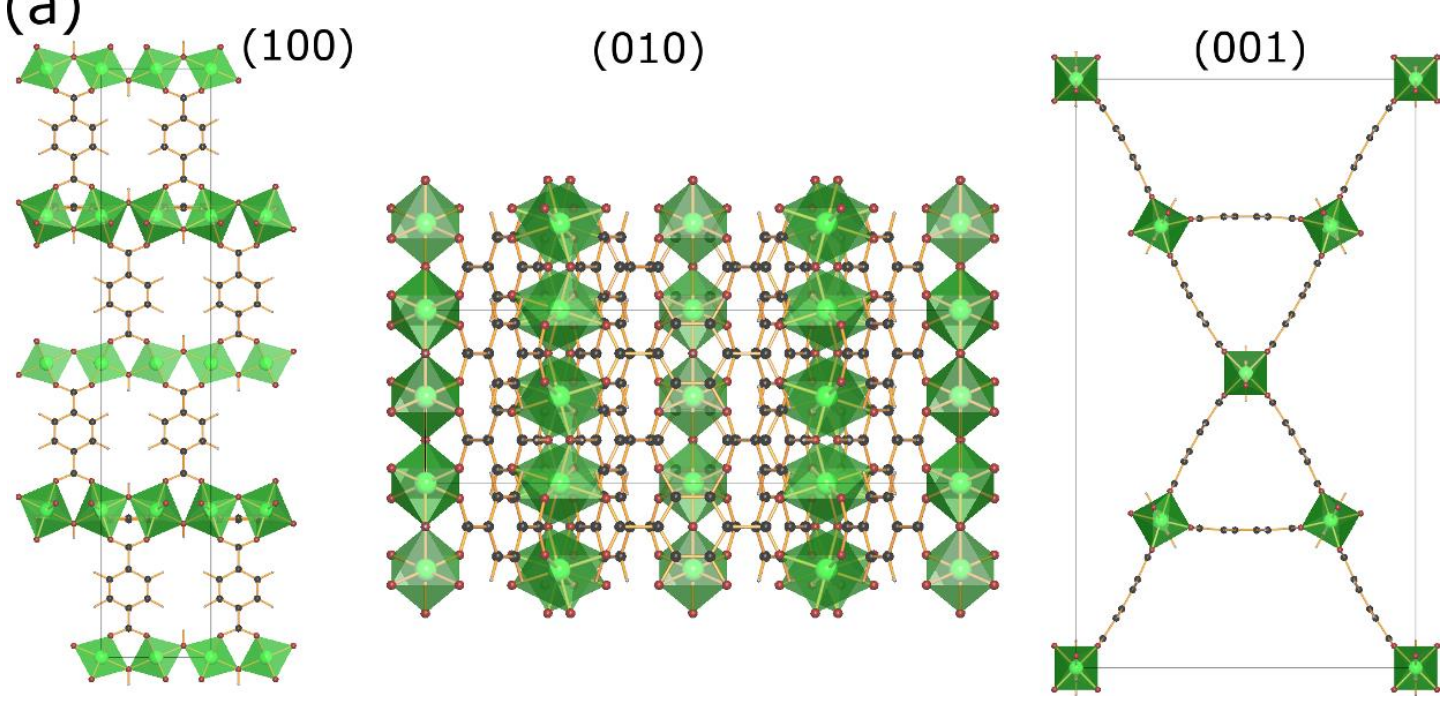

(b)
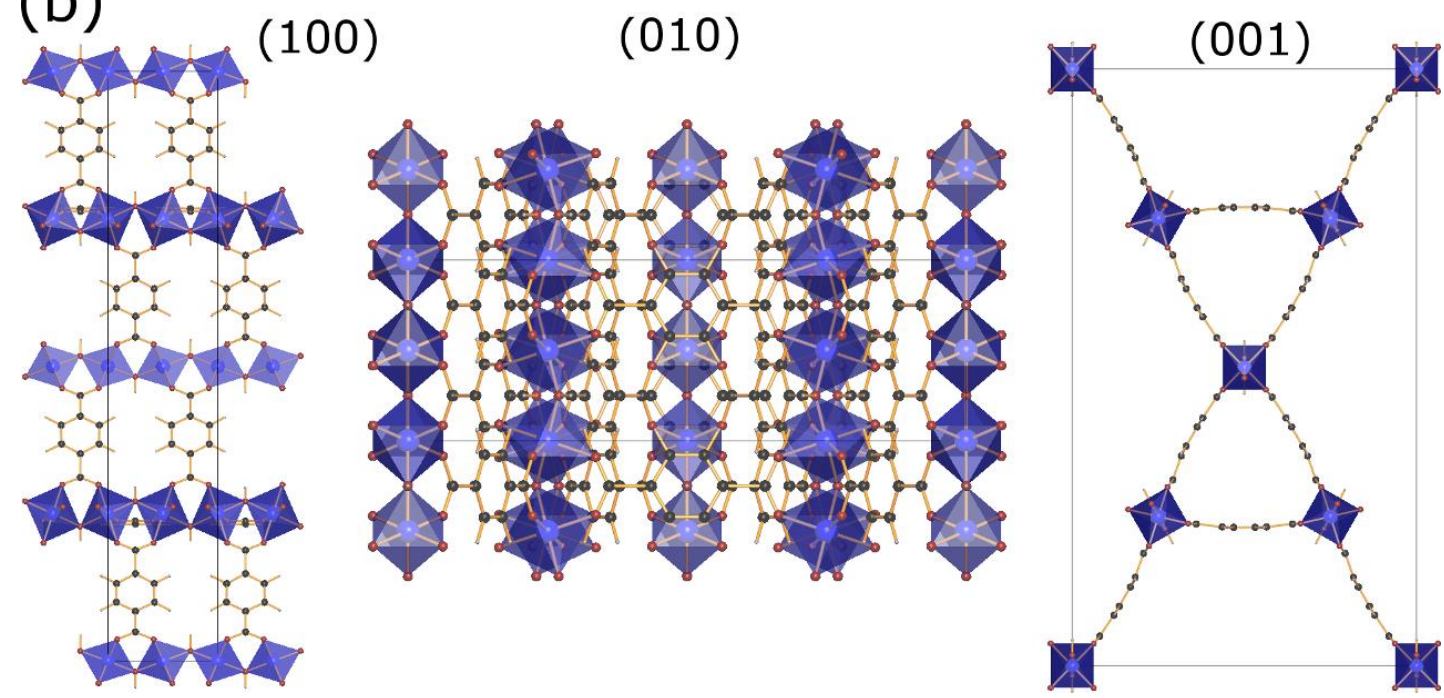

Figure S4. Crystallographic projections (100), (010), (001) of the crystal structures of (a) MIL68(Fe) (XADCOW) and (b) MIL-68(V) (ATOTIM).

The crystal structure of $\mathrm{Al}(\mathrm{OH})(1,4-\mathrm{ndc})$ is constructed from ditopic ligands and Al-containing rod SBUs with linear alignment of the metal atoms (Fig. S5). A very similar configuration is in the MIL-53 family, but instead of benzene-1,4-dicarboxylic acid the ligand in $\mathrm{Al}(\mathrm{OH})(1,4-\mathrm{ndc})$ is the bulkier naphthalene-1,4-dicarboxylic acid (1,4-ndcH $\mathrm{H}_{2}$. To avoid overlapping, the naphthalene rings are tilted by approximately $35^{\circ}$ with respect to plane (100), where the carboxylic groups reside. However, the framework is more symmetrical (tetragonal space group P4/nmm) than MIL-53 (orthorhombic crystal system Imma) and the channels have a 4-fold symmetry. These structural features provide robustness of the structure, its permanent porosity 
and remarkable thermal stability. The $\mathrm{Al}(\mathrm{OH})(1,4-\mathrm{ndc})$ has another topology (crb) and two types of square-shaped 1D channels occupying about $30 \%$ of the unit cell volume, and the framework does not undergo any structural transformation upon removing water molecules [14].
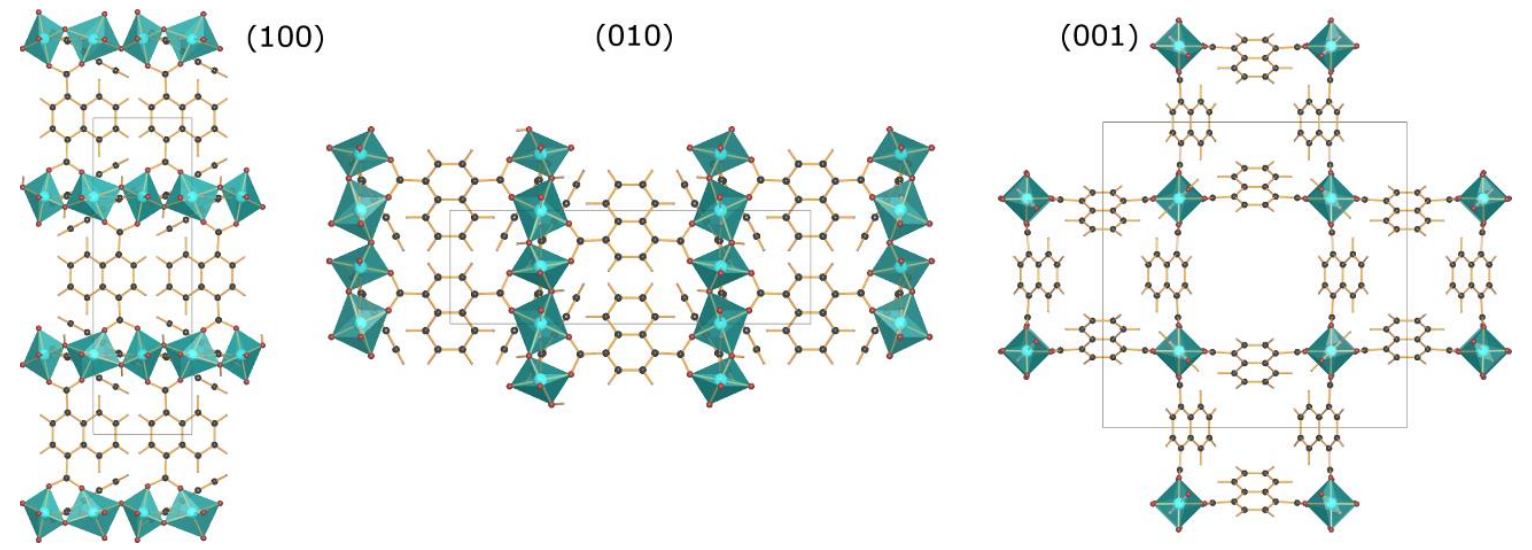

Figure S5. Crystallographic projections (100), (010), (001) of the crystal structure of $\mathrm{Al}(\mathrm{OH})(1,4-\mathrm{ndc}) \cdot 2 \mathrm{H}_{2} \mathrm{O}(\mathrm{WOJJOV})$.

The frameworks CAU-10- $X\left(X=\mathrm{H}, \mathrm{CH}_{3}, \mathrm{OCH}_{3}\right.$ [15], and $\mathrm{Br}$ [16]; Fig. S6) feature V-shaped 5- $X$ isophthalate linkers, $\mathrm{Al}$ central atoms, helical shape of the rods, and the gis underlying topology. The rod SBUs are oriented along the $c$ axis. There are four such helical SBUs per unit cell. The rods are bridged by $\mathrm{V}$-shaped 1,3-benzenedicarboxylate struts connecting the rods in two directions: along the $a$ and $b$ vectors of the unit cell. The rod SBUs are bridged by pairs of ligands with an in-plane orientation of the aromatic rings. Additional functional groups carried by the benzene rings of such a pair are always pointing out in opposite directions. Because the aromatic rings are rotated at an angle to the $c$ axis, it allows a denser packing of the $\mathrm{V}$-shaped organic fragments. Such a geometry configuration of the ligands causes the distorted helical shape of the rod SBUs. The frameworks have tetragonal symmetry $I 4_{1}(\mathrm{H}), I_{1} /$ amd $\left(\mathrm{Br}, \mathrm{CH}_{3}\right)$, $I 4_{1} / a\left(\mathrm{OCH}_{3}\right)$; they are porous with $1 \mathrm{D}$ channels occupying $31 \%, 26 \%, 25 \%$, and $25 \%$ of the unit cell, respectively. CAU-10 materials are highly stable that is confirmed by XRPD with varying temperature (up to $350^{\circ} \mathrm{C}$ ), $\mathrm{pH}$ in aqueous solution, and sorption of $\mathrm{N}_{2}, \mathrm{H}_{2}, \mathrm{CO}_{2}$ and $\mathrm{H}_{2} \mathrm{O}$. 
(a)
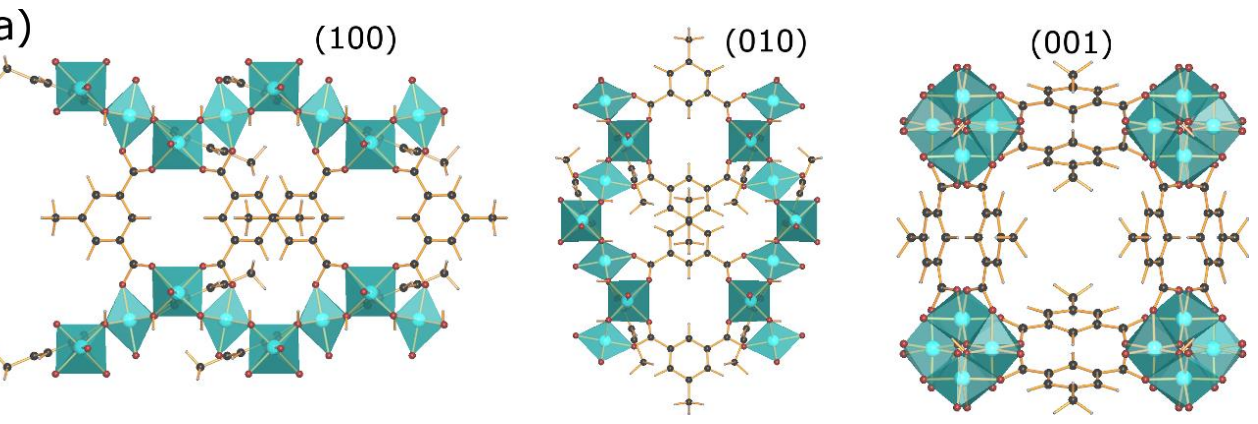

(b)

(100)
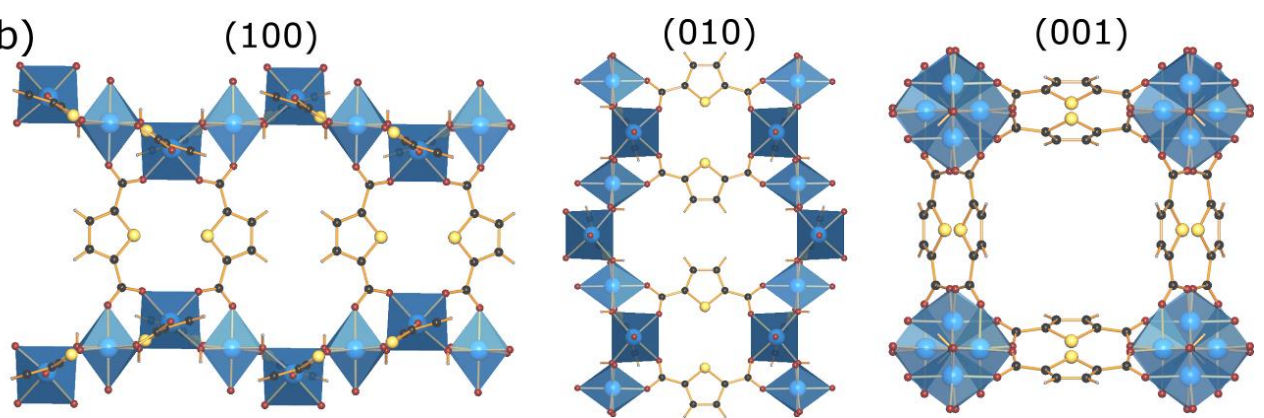

(c)

(100)
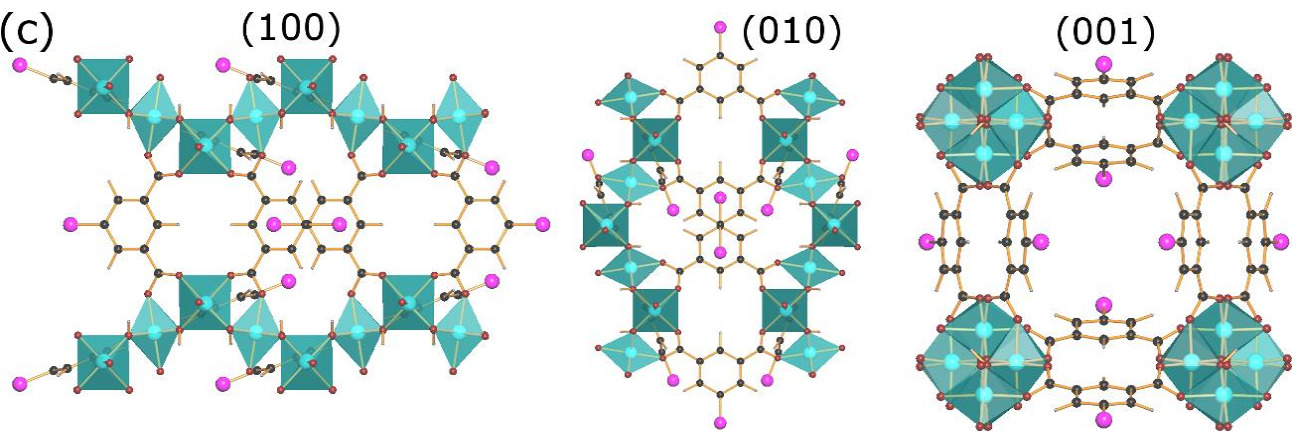

(d)

(100)
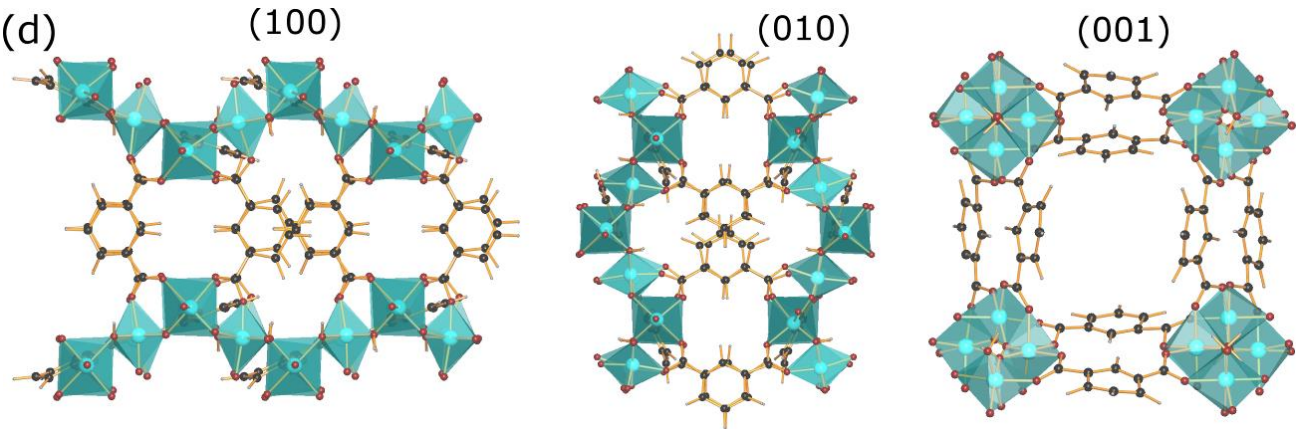

(e)

(100)
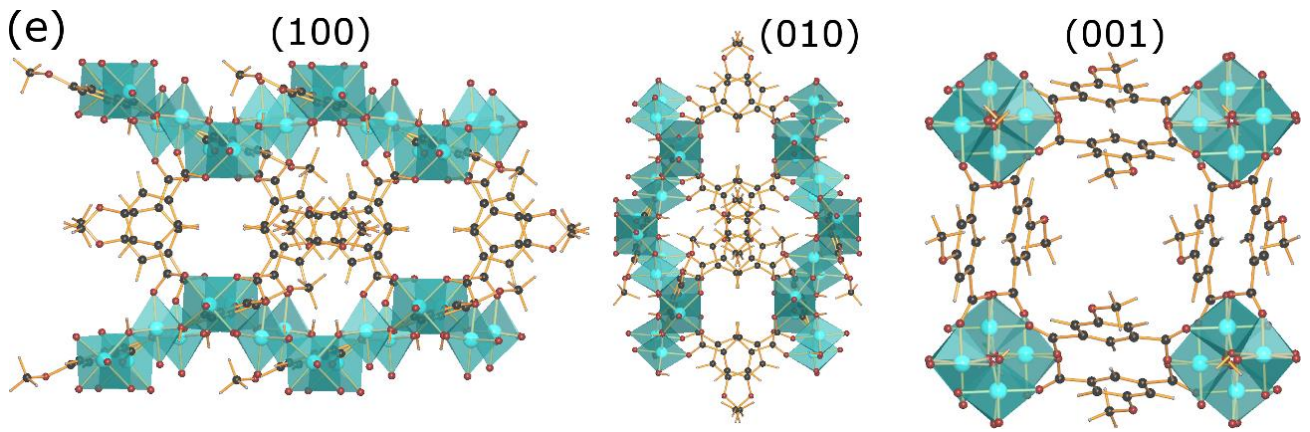

Figure S6. Crystallographic projections (100), (010), (001) of the crystal structures of (a) CAU10-CH 3 (CELZOK), (b) NOTT-401 (EXEQEE), (c) CAU-10-Br (PEYSUJ), (d) CAU-10-H (CELZUQ), and (e) CAU-10-OCH 3 (CELZIE). 
However, in-situ PXRD and molecular dynamics simulations revealed structural transition of the CAU-10-H framework upon water vapor adsorption accompanied by extension of rods [17]. The NOTT-401 framework [18] has the same type and symmetry $\left(I 4_{1} / a m d\right)$, but differs by Sc central atom of a larger atomic radius and by a longer thiophene-2,5-dicarboxylate ligand (Fig. S6b). As a result, the framework is more porous with a 3D system of accessible channels occupying 55\% of the unit cell.

Unusual bidirectional arrangement of rods is observed for the CAU-8(Al) framework (Fig. S7) featuring tetragonal symmetry $I 4_{1} / a$, V-shaped linker of 4,4'-benzophenonedicarboxylic acid, the 4/5/t 1 topology and 1D channels with a diameter of about $8 \AA$ (27\% of unit cell by volume) [19]. This structure has two sets of rod SBUs orthogonal to each other. Angular 4,4'carbonyldibenzoate ligands connect the Al-containing 1D SBUs of different orientations. The linkers are formed by a carbonyl group bonded to two benzene-1,4-carboxylate residues. The ligands connect perpendicularly oriented rod SBUs that is possible due to rotation of the benzene rings around the $\mathrm{C}-\mathrm{C}$ bond with carbonyl group. The structural motif is very similar to a more porous (47\%) JUC-77 framework, [ $\operatorname{In}(\mathrm{OH})\left(4,4^{\prime}\right.$-oxybisbenzoate)], showing remarkable breathing $[20,21]$. However, despite the similarity, CAU-8 possesses a non-compliant behaviour upon solvent removing.

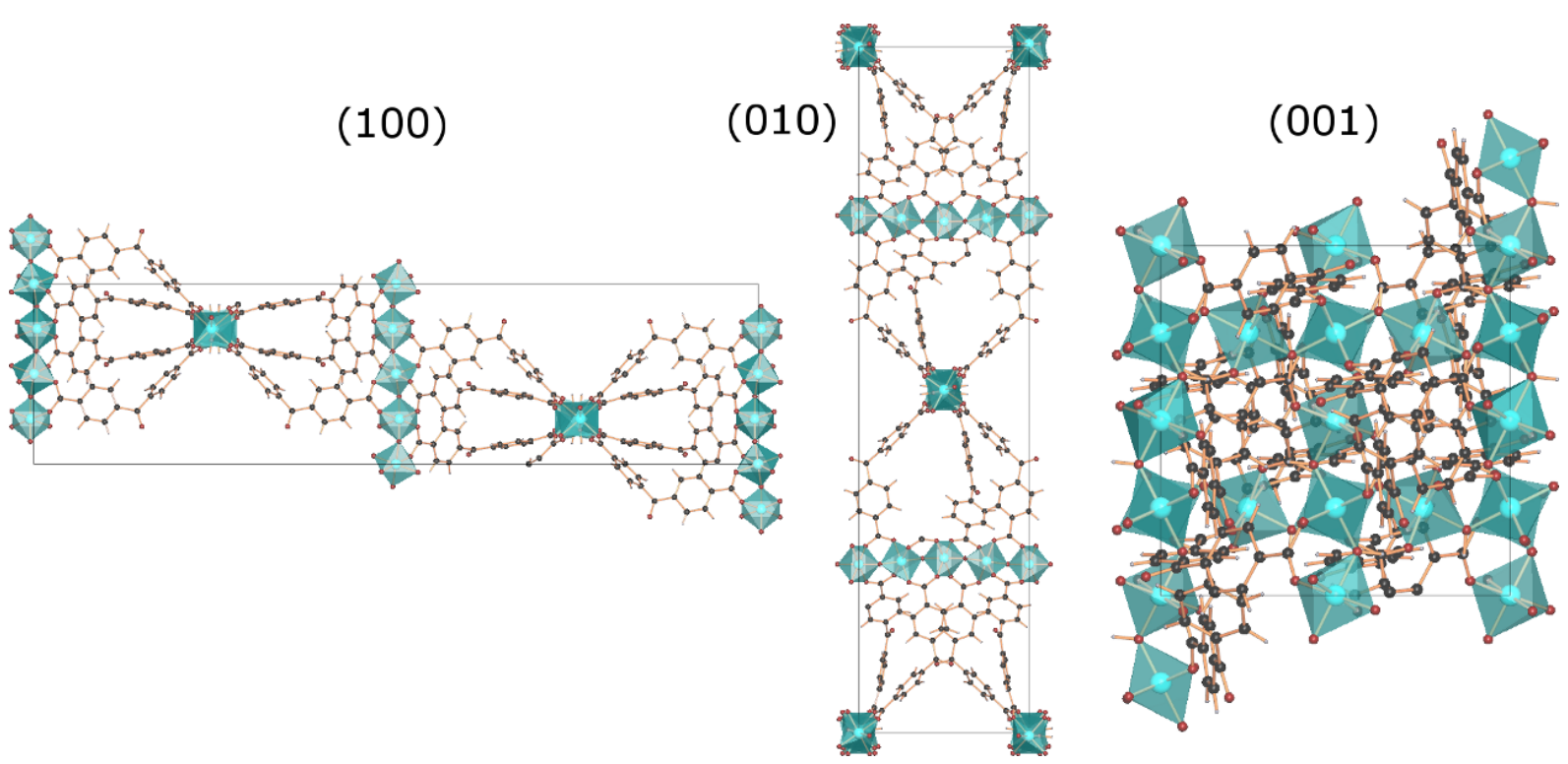

Figure S7. Crystallographic projections (100), (010), (001) of the crystal structure of CAU-8 (ZESZEE). 
Two porous isostructural frameworks of the cda underlying topology, NOTT-400 (accessible volume of 50\%) [19] and CPF-1 (51\%) [22], crystallize in tetragonal space group $I 4_{1} 22$ from solutions of a tetratopic ligand, biphenyl-3,3',5,5'-tetracarboxylic acid, and salts of Sc(III) and $\operatorname{Mg}(\mathrm{II})$ (Fig. S8). Both of them have a 4-fold right-handed helical shape caused by an out-ofplane conformation of the biphenyl-groups oriented along the rod direction [001]. The ligands connect the rods in pairwise manner in four equivalent directions [110], [-1-10], [1-10] and [-110]. The frameworks are porous with a wine-rack motif and square-prismatic channels along the $c$ axis. The rods in CPF- 1 have $\mathrm{H}_{2} \mathrm{O}$ ligands, while the NOTT-400 rods are constructed by $\mathrm{OH}^{-}$anions. The organic ligands have out-of-plane conformation and they are adjacent to two rods that results in helical shape of the rods and 1D channels along rods (of diameter $8.1 \AA$ ), but in comparison to CAU-10 family the two compounds do not show breathing.
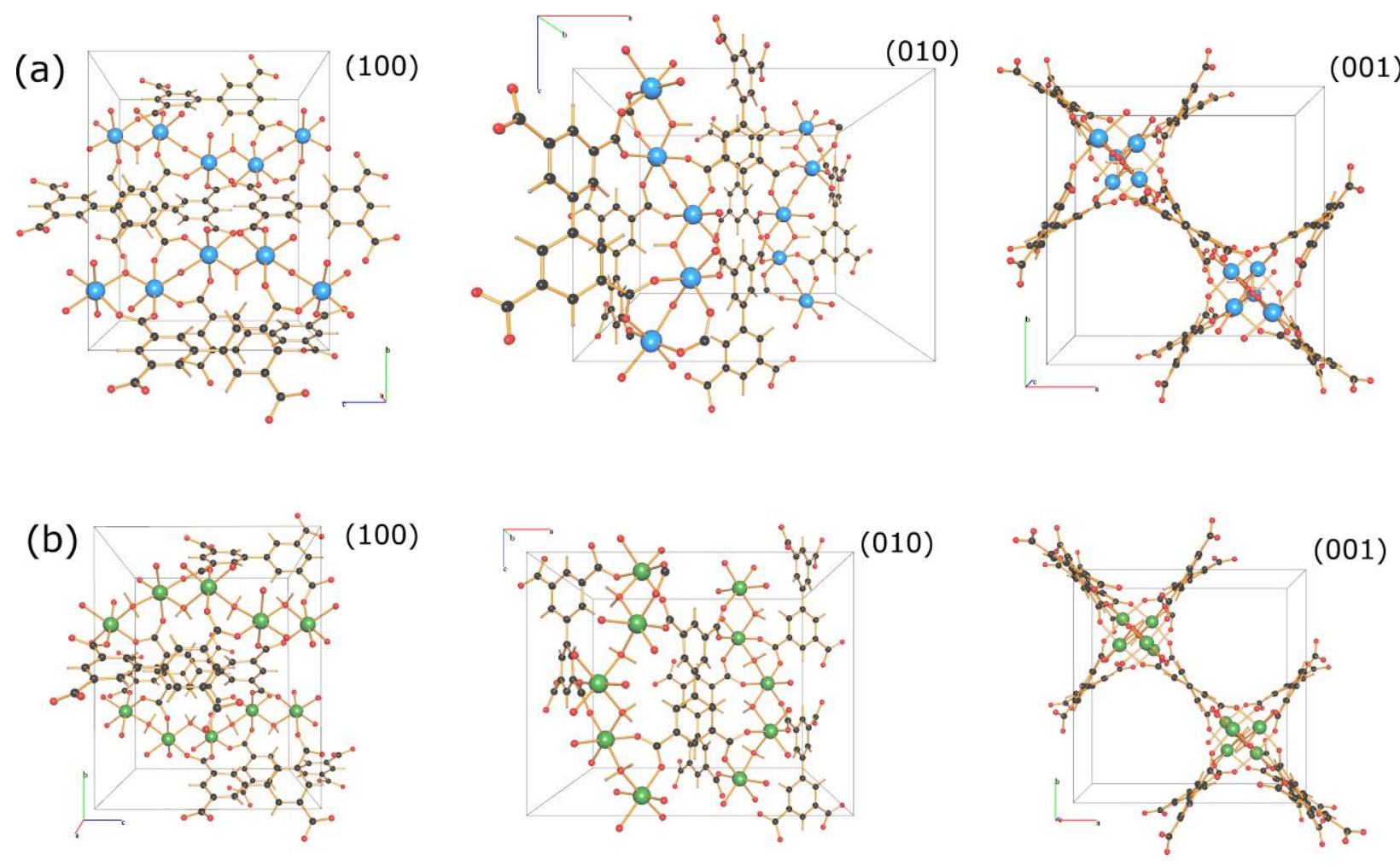

Figure S8. Crystallographic projections (100), (010), (001) of the crystal structures of (a) NOTT-400 (EXEQII), and (b) CPF-1 (HAFVUH). 
The crystal structures of MIL-118(Al) [23] and MIL-60(V) [24] of the mog underlying topology (Fig. S9) are also constructed from tetratopic ligand, benzene-1,2,4,5-tetracarboxylic acid, but the linkers connect four rods. The rods have a straight shape. Despite the isoreticularity, MIL-60 and MIL-118 are isomeric and differ by positions of the carboxylate groups in benzene ring of ligand $(1,2-4,5$ vs $1,5-2,4)$ with respect to the inter-rod connections (Fig. S10). As a result, the geometry of frameworks is also different. In an orthorhombic cell (Pbam) of MIL-118, the planes of the benzene-1,2,4,5-tetracarboxylate ligands are alternatively inclined to the rods with angles $64.2^{\circ}$ and $154.2^{\circ}$, but the average plane of them is orthogonal to the rod direction [010]. In contrary, in MIL-60 all benzene-1,2,4,5-tetracarboxylate ligands are aligned parallel to each other. They have an angle of $58.9^{\circ}$ with the rods, which results in a triclinic unit cell (P-1). Depending on the line-plane angle between the rods and benzene rings of ligands in MIL-118 and MIL-60, 2D and 1D systems of accessible channels orthogonal to the rods are observed with $26 \%$ or $28 \%$ of the unit cell volume, respectively. Hydration process induces a phase transition in the dried MIL-118(Al) with 6\% variation of the unit cell volume that is accompanied by a variation in orientation of the ligands with respect to the rods.

The orthorhombic ( $\mathrm{Cmcm}$ ) framework MIL-116(Al) (Fig. S9b) belongs to the same topological type mog and is similar to MIL-118, but the ligand has two additional carboxylic groups, which fill the pore space leaving only 1D channels with $13 \%$ of the unit cell volume [25]. In MIL-116, the benzene ring of the ligand is almost orthogonal $\left(81.7^{\circ}\right)$ to the rod direction [010]. The channels are of a rectangular shape $4.0 \times 2.7 \AA$ and they are large enough for adopting and migration of water molecules, but the dehydration induces no structural changes in the framework geometry. 
(a)

(100)

(010)

(001)
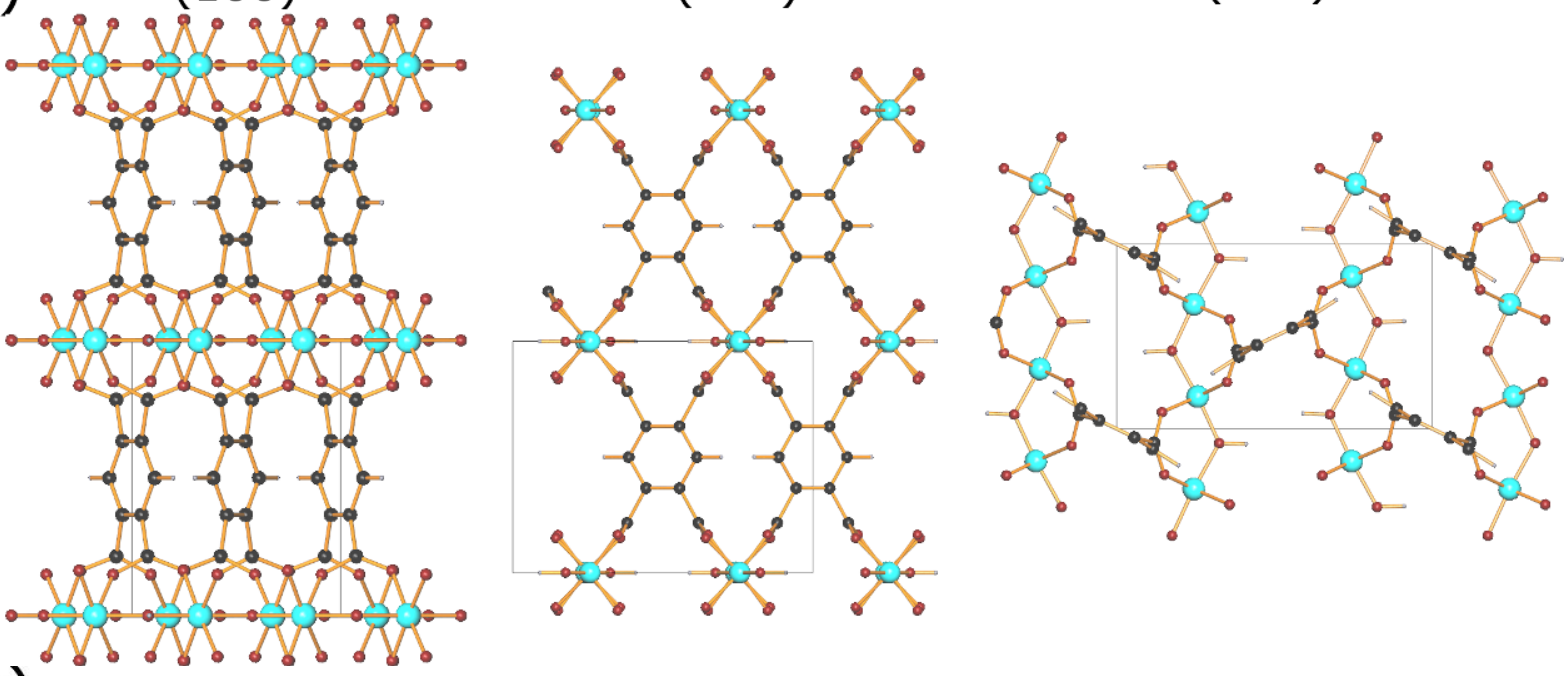

(b)

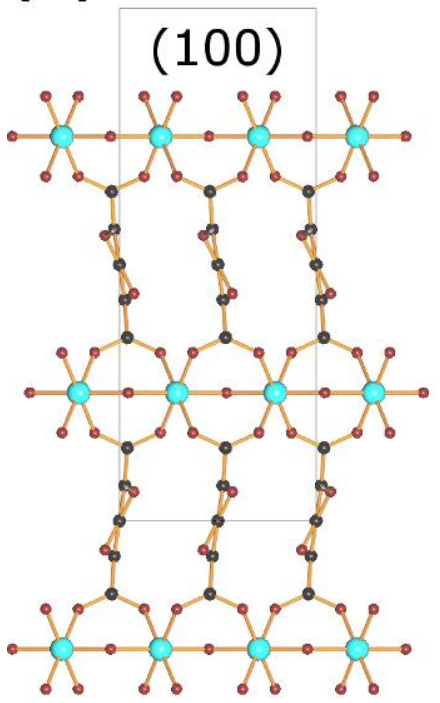

(c) (100)

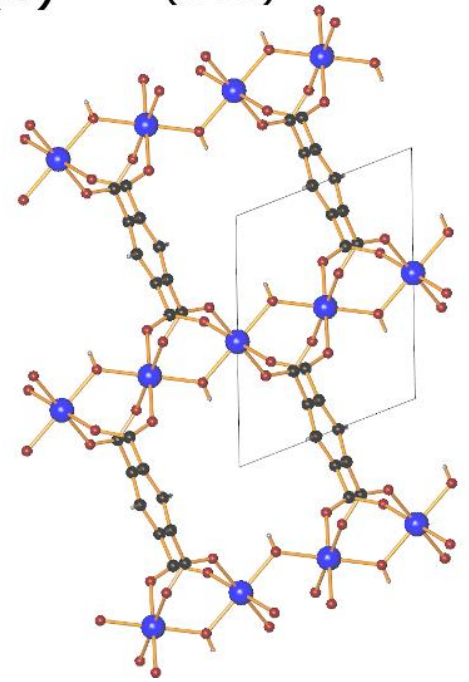

(010)

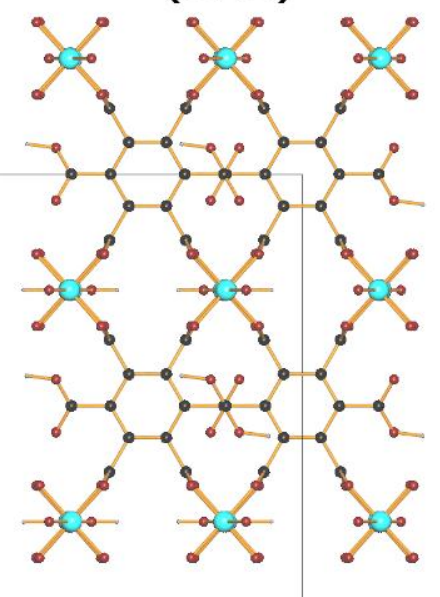

(010)
(001)

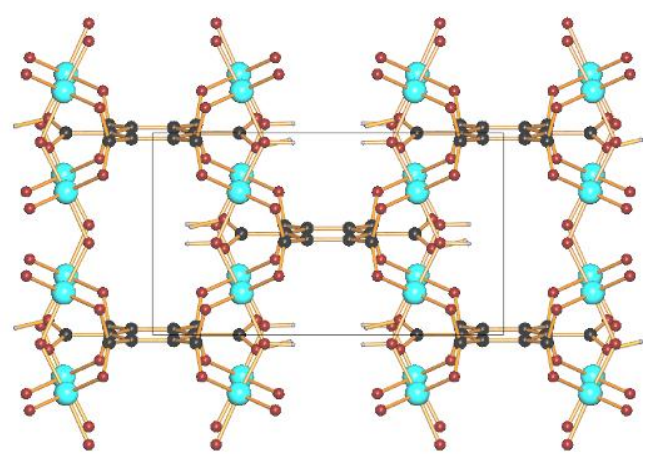

(001)

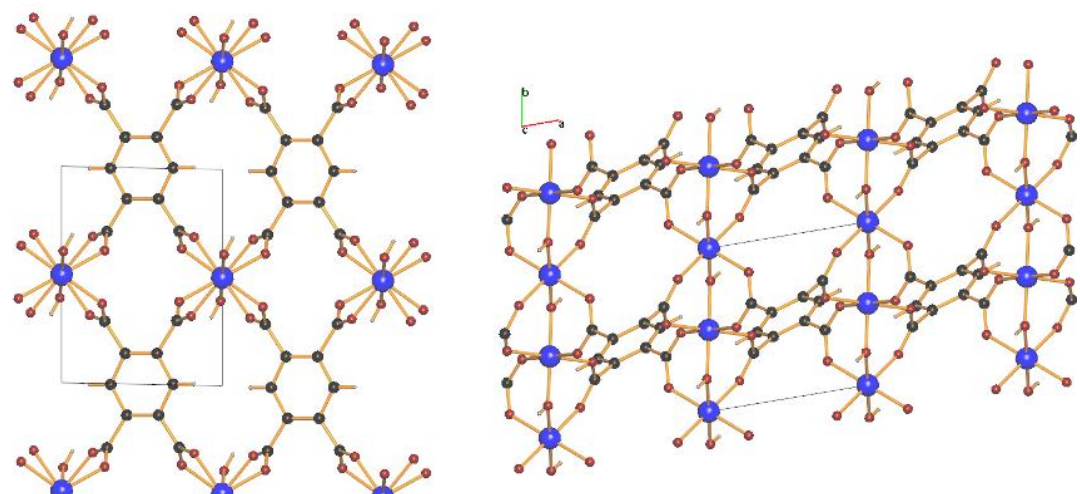

$8.0 \%$

Figure S9. Crystallographic projections (100), (010), (001) of the crystal structures of (a) MIL118 (GUKVEO), (b) MIL-116 (XOCROY), and (c) MIL-60 (GUXQAR). 

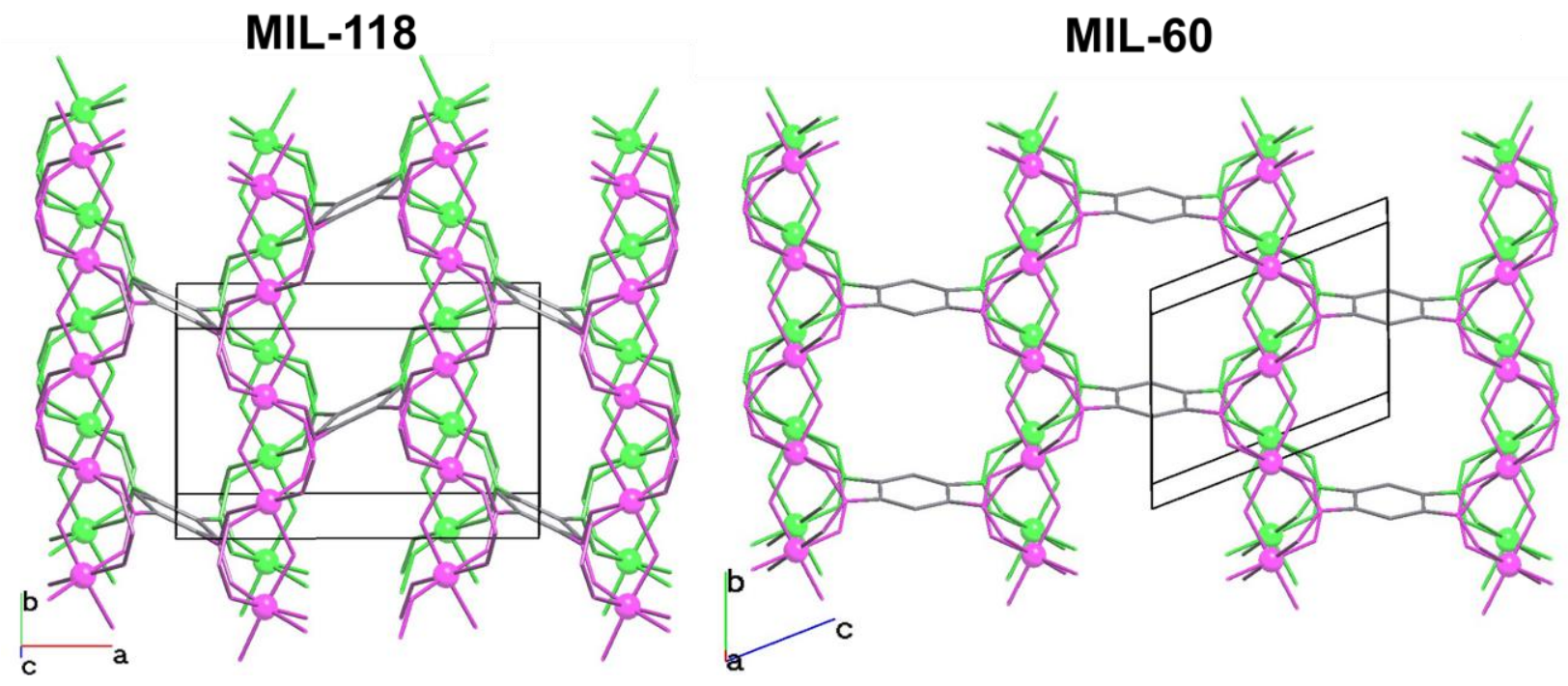

Figure S10. The crystal structures of isoreticular, but isomeric MIL-118 (GUKVEO) and MIL-60 (GUXQAR).

Two other isostructural monoclinic $\left(P 2_{1} / c\right)$ frameworks of the MIL-122 family belong to the same mog topological type with $\mathrm{Al}(\mathrm{III})$ and $\mathrm{Ga}(\mathrm{III})$ central atoms connected by voluminous 1,4,5,8-naphthalenetetracarboxylate anions (Fig. S11) [26]. The ligands are inclined to the rods with much less angles $\left(31^{\circ}\right.$ and $121^{\circ}, 30^{\circ}$ and $120^{\circ}$, respectively). The rods are aligned in the [001] direction. The wide aperture of the ligand is oriented along the (100) direction and the narrow aperture have two orientations of the corresponding short edges of the rectangular coordination figure in plane (100) with $49^{\circ}$ and $139^{\circ}$ to $c$ axis. Despite the linker elongation, the frameworks are less porous than MIL-118 and MIL-60 with only $14 \%$ for the $2 \mathrm{D}$ channel system. This is due to the presence of additional $(\mathrm{OC}) \mathrm{O} \cdots \mathrm{H}(\mathrm{O})$ bonds between the neighboring rods, which compact the framework. In MIL-122, no trapped species are observed and no structural change is visible upon immersion in different organic solvents (MeOH, DMF) that reflects its non-compliant nature. 
(a)

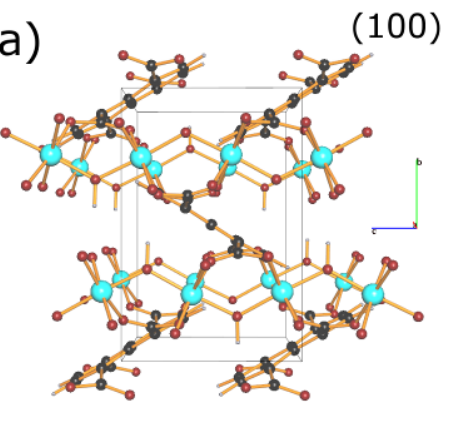

(b)

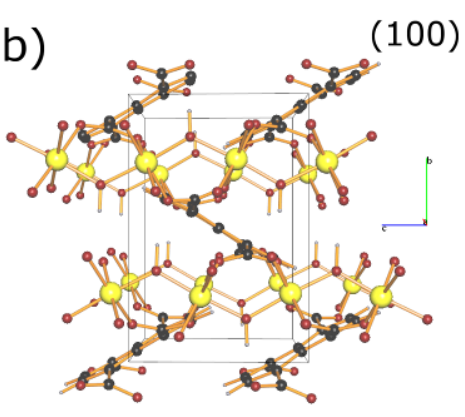

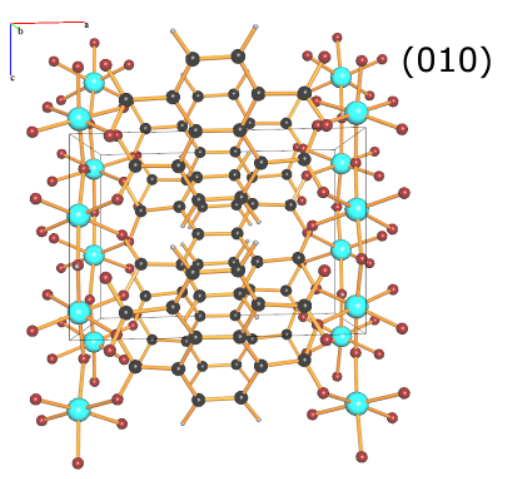

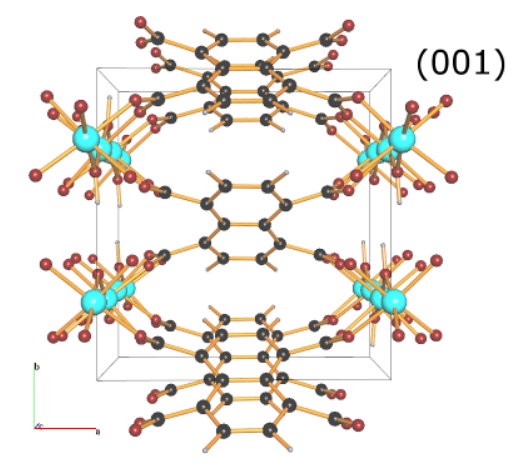

(010)
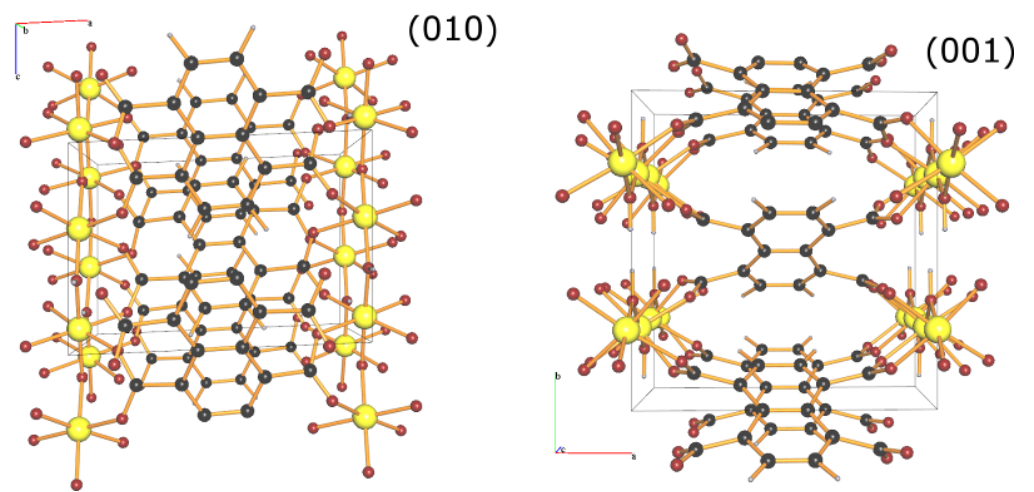

Figure S11. Crystallographic projections (100), (010), (001) of the crystal structures of (a) MIL122(Al) (NUFYAP), and (b) MIL-122(Ga) (NUFYET). 


\section{Section 3. Description of Young's modulus tensors for the 22 MOFs}

\section{MIL-53, MIL-61, MIL-121}

The shape of the elastic tensors for these three families is similar (Fig. S12, S13, S14). The structures have six maxima of the Young's modulus coinciding with orientations of the rods and ligands. In all cases, the ligand directions are stiffer than the rod directions as the Young's modulus varies in ranges 67-96 GPa and 32-58 GPa, respectively (Table S10). The stiffness of the rods and ligands in the MIL-53 series depends on the type of the central atom and grows in the following order: $\mathrm{Ga}, \mathrm{V}, \mathrm{Al}, \mathrm{Fe}$. In MIL-53, the minima of the Young's modulus (0.8-1.4 GPa) are achieved in the wide and narrow apertures of the channels.

The channels in MIL-61(V) are reinforced by a 2D H-bonded pattern. Hence, MIL-61(V) shows a higher Young's modulus of the wide diagonal of channel (Table S10, Figure S12), and the minimum corresponds to the direction intermediate between the rod and ligand [011] with the value of $14.5 \mathrm{GPa}$.

In MIL-121, the Young's modulus values $20.2 \mathrm{GPa}$ and $23.0 \mathrm{GPa}$ of the two minima corresponding to the narrow (in plane (010)) and wide (in plane (100)) diagonals of the lozengelike channels are also enhanced in comparison to MIL-53. However, if the direction of the minimum in plane (100) is oriented orthogonally to the rod direction [001], the vector of the minimum in plane (010) forms an angle $\theta$ of $58.7^{\circ}$ to $c$ axis (Fig. S13).

In the low-symmetric frameworks MIL-53(Fe) and MIL-53(Ga), the induced distortions led to a slight rotation of the peaks of the elastic tensor in the (010) plane (Fig. S12b and S12c). 

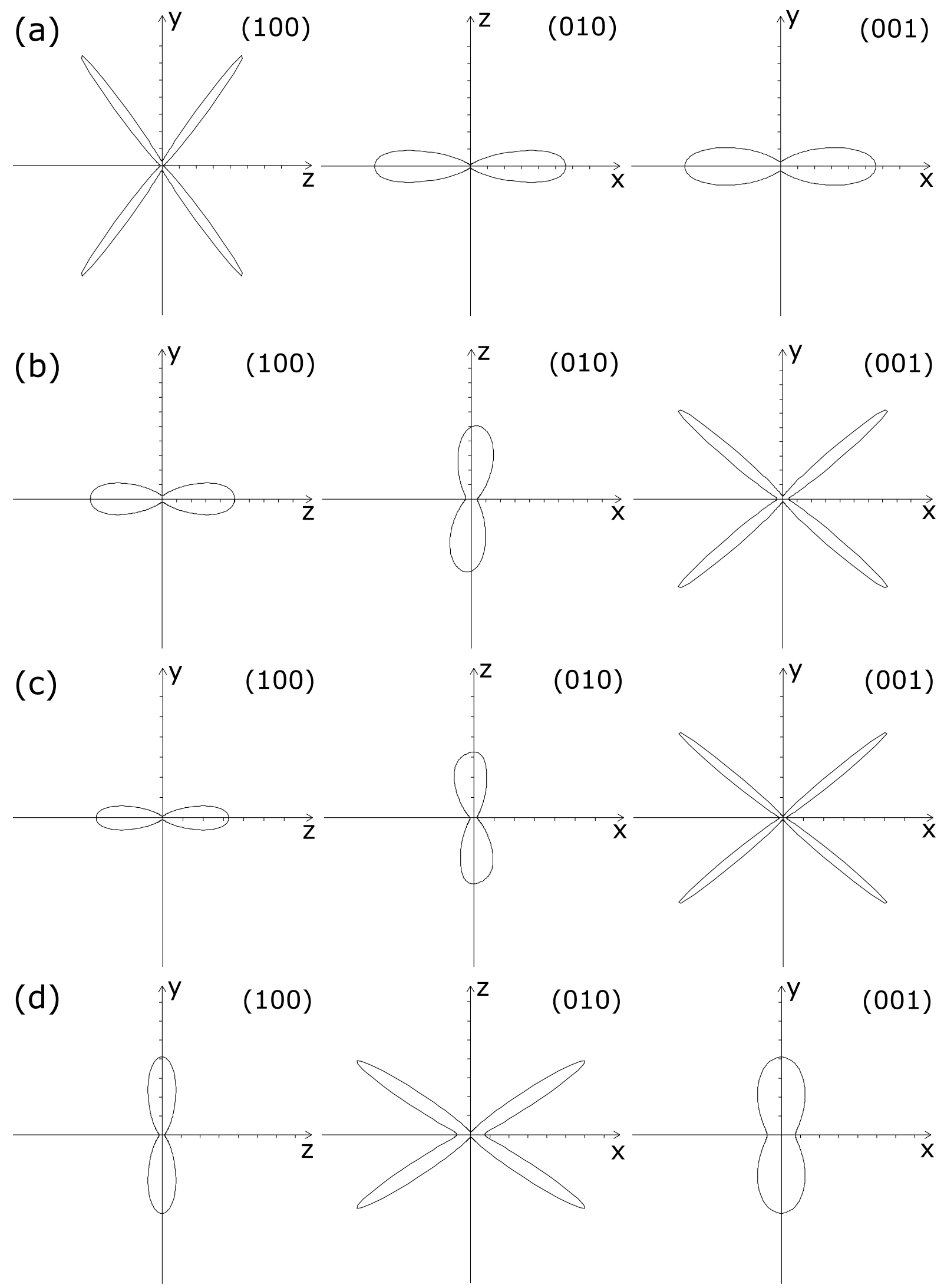

Figure S12. Cartesian projections of the elastic tensor of (a) MIL-53(Al) (SABVUN), (b) MIL53(Fe) (POJTOY), (c) MIL-53(Ga) (LOQLIN01), and (d) MIL-53(V) (ASOHUL). 


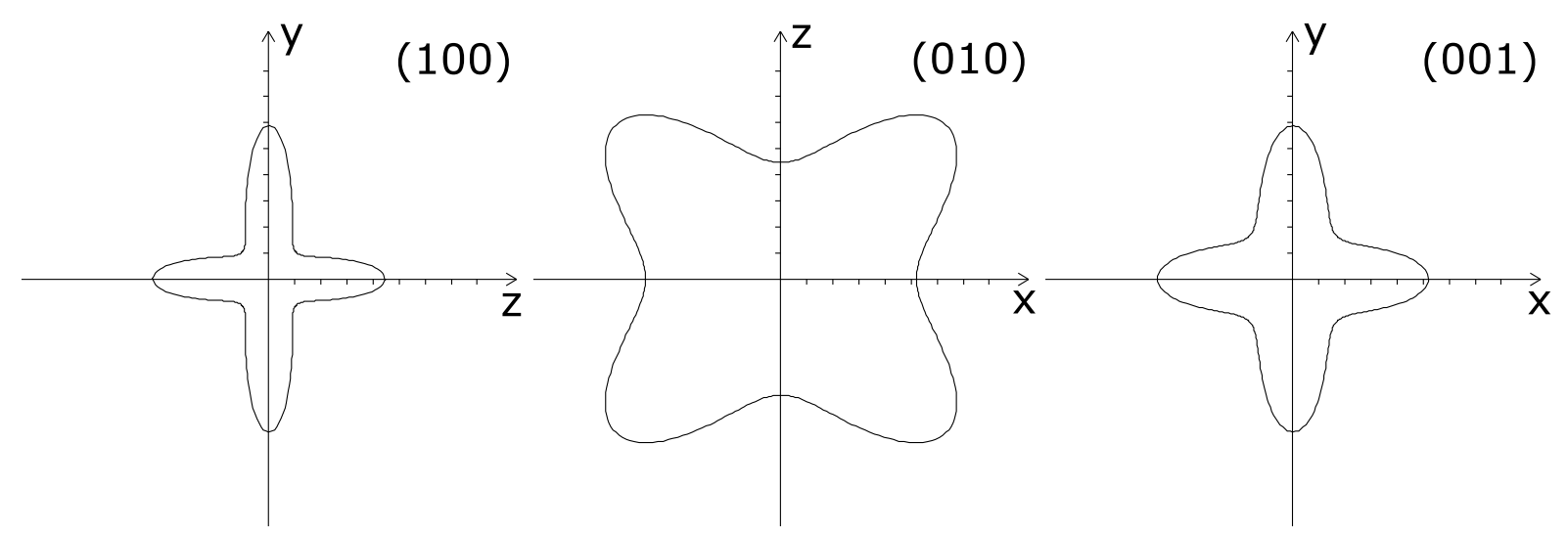

Figure S13. Cartesian projections of the elastic tensor of MIL-61 (GUXQEV).

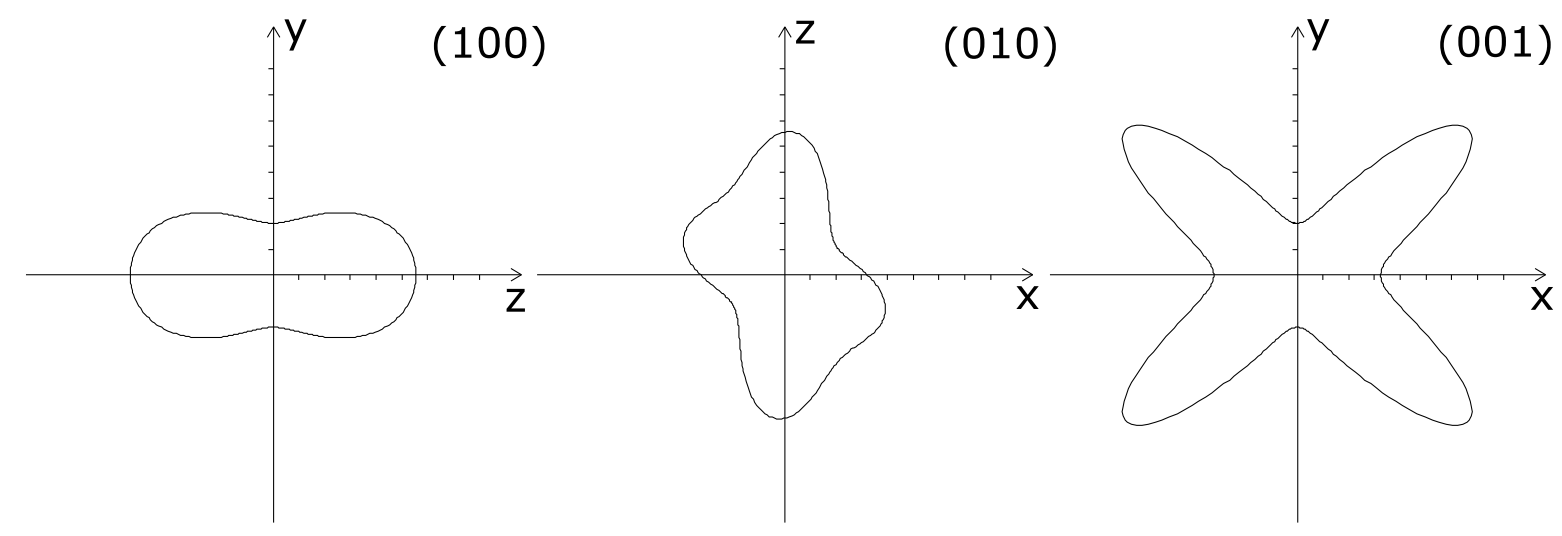

Figure S14. Cartesian projections of the elastic tensor of MIL-121 (RAWZIA).

Table S10. Young's modulus (GPa) along specific directions of MIL-53, MIL-121, MIL-61

\begin{tabular}{|l|l|l|l|l|l|l|}
\hline $\begin{array}{l}\text { Structural } \\
\text { species along } \\
\text { specific } \\
\text { direction }\end{array}$ & MIL-53(Al) & MIL-53(V) & MIL-53(Ga) & MIL-53(Fe) & MIL-121(Al) & MIL-61(V) \\
\hline Rod & 56.0 & 41.0 & 32.6 & 50.4 & 55.7 & 58.7 \\
\hline Ligand & 79.9 & 71.4 & $66.7,67.0$ & $96.0,96.4$ & 87.4 & $86.5,86.6$ \\
\hline $\begin{array}{l}\text { Narrow } \\
\text { diagonal of } \\
\text { channel }\end{array}$ & 0.8 & 1.4 & 0.8 & 2.2 & 20.1 & 44.6 \\
\hline $\begin{array}{l}\text { Wide diagonal } \\
\text { of channel }\end{array}$ & 2.7 & 7.4 & 1.7 & 4.0 & & \\
\hline
\end{tabular}




\section{MIL-68}

The stiffest directions coincide with $a$ and $c$ axes, which coincide with the orientations of ligands and rod SBUs, respectively (Fig. S15, Table S11). Two orientations of ligands, [110] and [1-10] do not give separate peaks and provide one maximum along the $b$ axis.
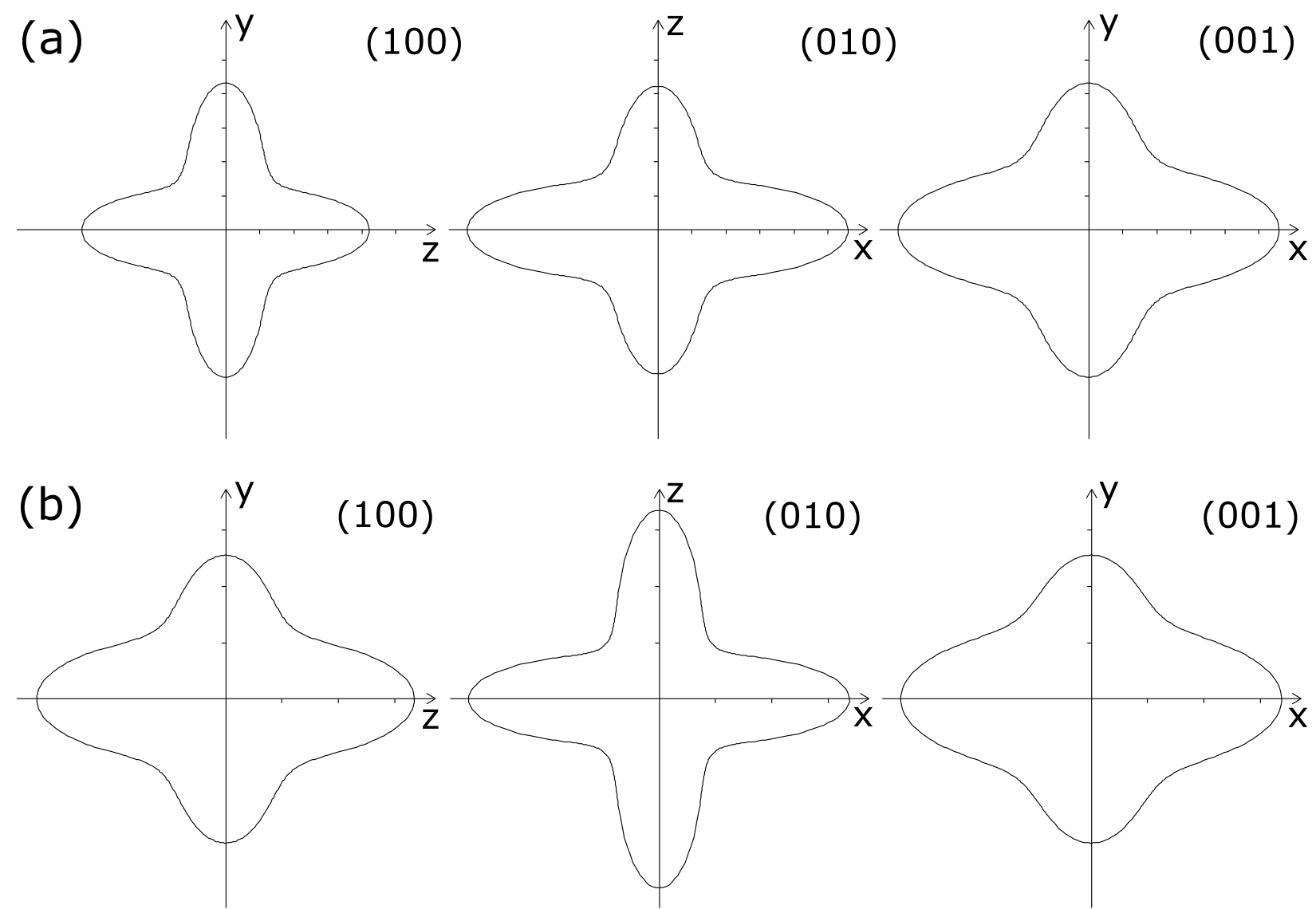

Figure S15. Cartesian projections of the elastic tensor of (a) MIL-68(Fe) (XADCOW) and (b) MIL-68(V) (ATOTIM).

Table S11. Young's modulus (GPa) along specific directions for the MIL-68 MOFs

\begin{tabular}{|l|l|l|l|}
\hline Structural species along specific direction & Direction & MIL-68(V) & MIL-68(Fe) \\
\hline Rod & {$[001]$} & 33.4 & 42.3 \\
\hline Ligand & {$[100]$} & 33.7 & 55.9 \\
\cline { 2 - 4 } & {$[110]$} & 20.0 & 31.0 \\
\hline Wide aperture of channel & {$[110]$} & 19.2 & 28.9 \\
\hline Narrow aperture of channel & $(010)$ & 25.5 & 43.1 \\
\hline
\end{tabular}




\section{$\mathrm{Al}(\mathrm{OH})(1,4-\mathrm{ndc})$}

Because of a structural similarity of $\mathrm{Al}(\mathrm{OH})(1,4-\mathrm{ndc})$ and MIL-53, the Young's moduli of both structures have tensor surfaces of the same shape (Fig. S16). Along the ligands, the stiffness of both structures is similar: $79.9 \mathrm{GPa}$ in $\mathrm{MIL}-53(\mathrm{Al})$, and $78.9 \mathrm{GPa}$ in $\mathrm{Al}(\mathrm{OH})(1,4-\mathrm{ndc})$. The rod direction also reaches maximum with a similar value of 50.0 GPa. However, the minimum of the Young's modulus corresponding to the diagonal direction of the square channels is of one order of magnitude higher: 9.1 of $\mathrm{Al}(\mathrm{OH})(1,4-\mathrm{ndc}) \mathrm{GPa}$ ss $0.8 \mathrm{GPa}$ of MIL-53 (Table S8).
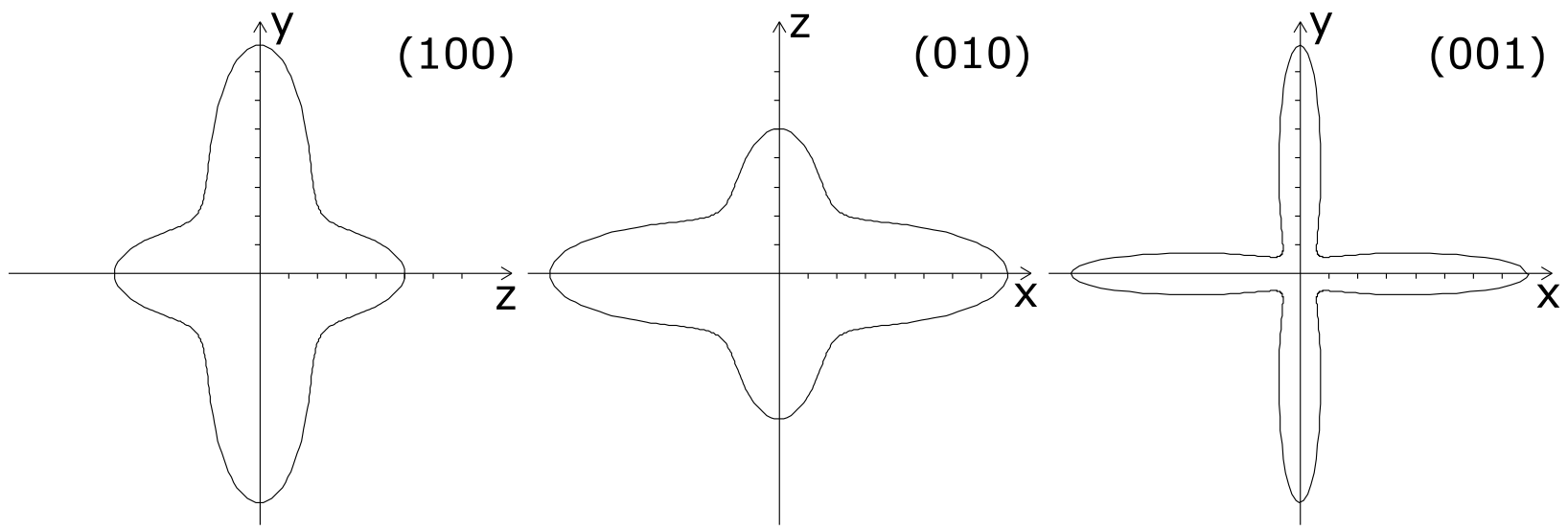

Figure S16. Cartesian projections of the elastic tensor of $\mathrm{Al}(\mathrm{OH})(1,4-\mathrm{ndc}) \cdot 2 \mathrm{H}_{2} \mathrm{O}$ (WOJJOV).

\section{NOTT-401 and CAU-10}

In the NOTT-401 and CAU-10 crystal structures two wide lobes of the Young's moduli maxima occur along the $a$ and $b$ axes, which are related to the linkers (Fig. S17, Table S12). The helical rod SBUs along the $c$ axis has a lowest stiffness, as demonstrated by the minimum of the Young's modulus, while the diagonal directions are stiffer $\left(\mathrm{CAU}-10-\mathrm{CH}_{3}, \mathrm{CAU}-10-\mathrm{OCH}_{3}\right.$, CAU-10-Br) or of about the same value (NOTT-401, CAU-10-H).

The average Young's modulus (by Voigt) shows that the framework stiffness decreases in the order $\mathrm{CAU}-10-\mathrm{Br}>\mathrm{CAU}-10-\mathrm{OCH}_{3}>\mathrm{CAU}-10-\mathrm{CH}_{3}>\mathrm{CAU}-10-\mathrm{H}>\mathrm{NOTT}-401 \quad$ (Table S8). This order correlates with increasing porosity of the frameworks. 

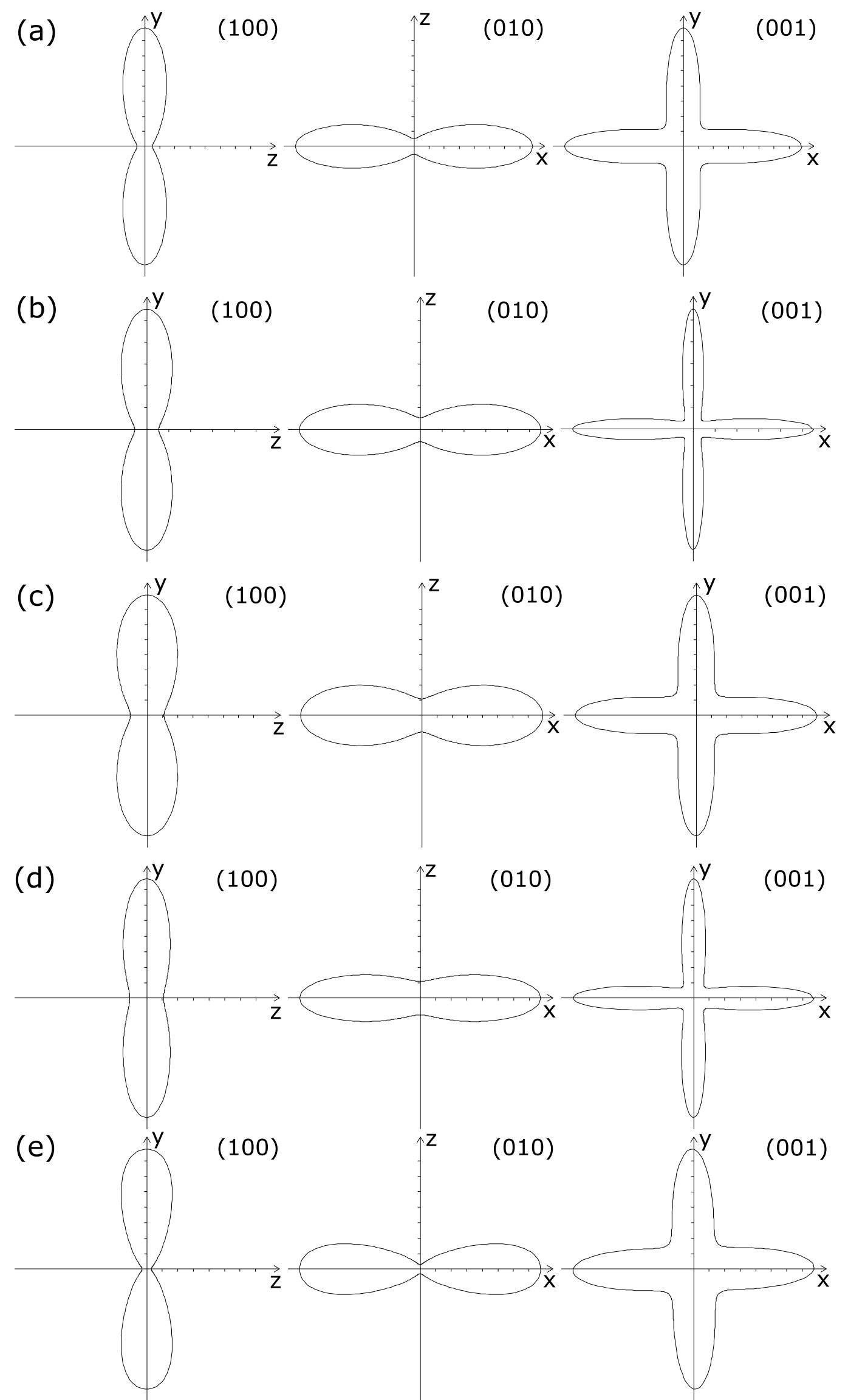

Figure S17. Cartesian projections of the elastic tensor of (a) $\mathrm{CAU}-10-\mathrm{CH}_{3}$ (CELZOK), (b) NOTT-401 (EXEQEE), (c) CAU-10-Br (PEYSUJ), (d) CAU-10-H (CELZUQ), and (e) CAU$10-\mathrm{OCH}_{3}(\mathrm{CELZIE})$. 
Table S12. Young's modulus (GPa) along specific directions for the NOTT-401 and CAU-10

\begin{tabular}{|l|l|l|l|l|l|}
\hline Structural species along & NOTT- & CAU- & CAU- & CAU-10- & CAU- \\
specific direction & 401 & $10-\mathrm{H}$ & $10-\mathrm{CH} 3$ & OCH3 & $10-\mathrm{Br}$ \\
\hline Rod & 5.5 & 10.8 & 5.1 & 2.9 & 11.0 \\
\hline Ligand & 55.1 & 77.2 & 78.4 & 77.6 & 79.7 \\
\hline Diagonal of channel & 5.8 & 10.1 & 17.9 & 22.7 & 19.7 \\
\hline
\end{tabular}

\section{CAU-8}

In MOFs with linear rod SBUs, one of the most rigid direction is along the SBUs. On the contrary, CAU-8 is stiffer in the direction perpendicular to the rods (Fig. S18), i.e. along the $c$ axis (23.9 GPa). The rod directions [100] and [010] coincide with apertures of channels, and the stiffness along $a$ and $b$ is twice less $(12.5 \mathrm{GPa})$ than along $c$. The tensor minimum of $9.4 \mathrm{GPa}$ is located approximately along (110), with an angle of $53^{\circ}$ to $a$. The softest directions in CAU-8 correspond to orientation of the $\mathrm{C}-\mathrm{C}$ bonds of the benzene rings with the carbonyl group of the 4,4'-cdb linkers. The CAU-8 framework has the lowest average Young's modulus (11.0 GPa) among the MOFs under consideration (Table S8).

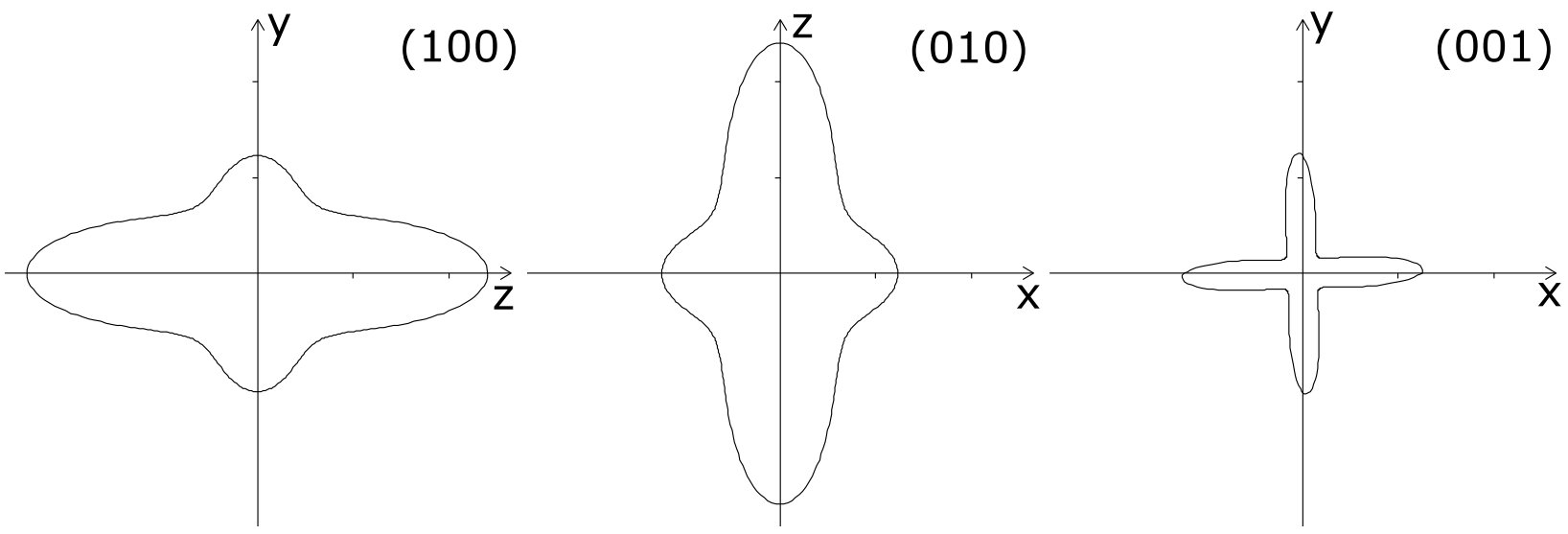

Figure S18. Cartesian projections of the elastic tensor of CAU-8 (ZESZEE). 


\section{NOTT-400 and CPF-1}

The shapes of the elastic tensors of NOTT-400 and CPF-1 are almost the same, which is due to similarity of the structures (Fig. S19). The directional Young's moduli show six maxima forming two groups of symmetrically equivalent peaks: parallel to the rods, and in directions [110], [-110], [1-10], [-110] along the connections of the rods to ligands. The peaks along the rods are two times higher (85.6 and $72.4 \mathrm{GPa}$ ) in comparison to those along the inter-rod connections (41.5 and $34.8 \mathrm{GPa}$ ). That is because the biphenyl groups of the ligands are oriented along the rods and contribute in the reinforcement of the framework in this direction. A helical shape of the rods allows the carboxyl-groups to tilt around the rod axes, making the directions along the ligands softer. In directions [100] and [010], the Young's moduli display equivalent minima along the diagonals of the channels: 5.6 GPa for NOTT-400 and 2.9 GPa for CPF-1. Expectedly, NOTT400 containing $\mathrm{Sc}^{3+}$ is stiffer than $\mathrm{CPF}-1$ with $\mathrm{Mg}^{2+}$ cation in the rod direction. However, the latter has stiffer diagonals of channels due to additional H-bonding between hydrogen atoms of water molecules and oxygen atoms of the - $\mathrm{COO}$ groups of the same rod.

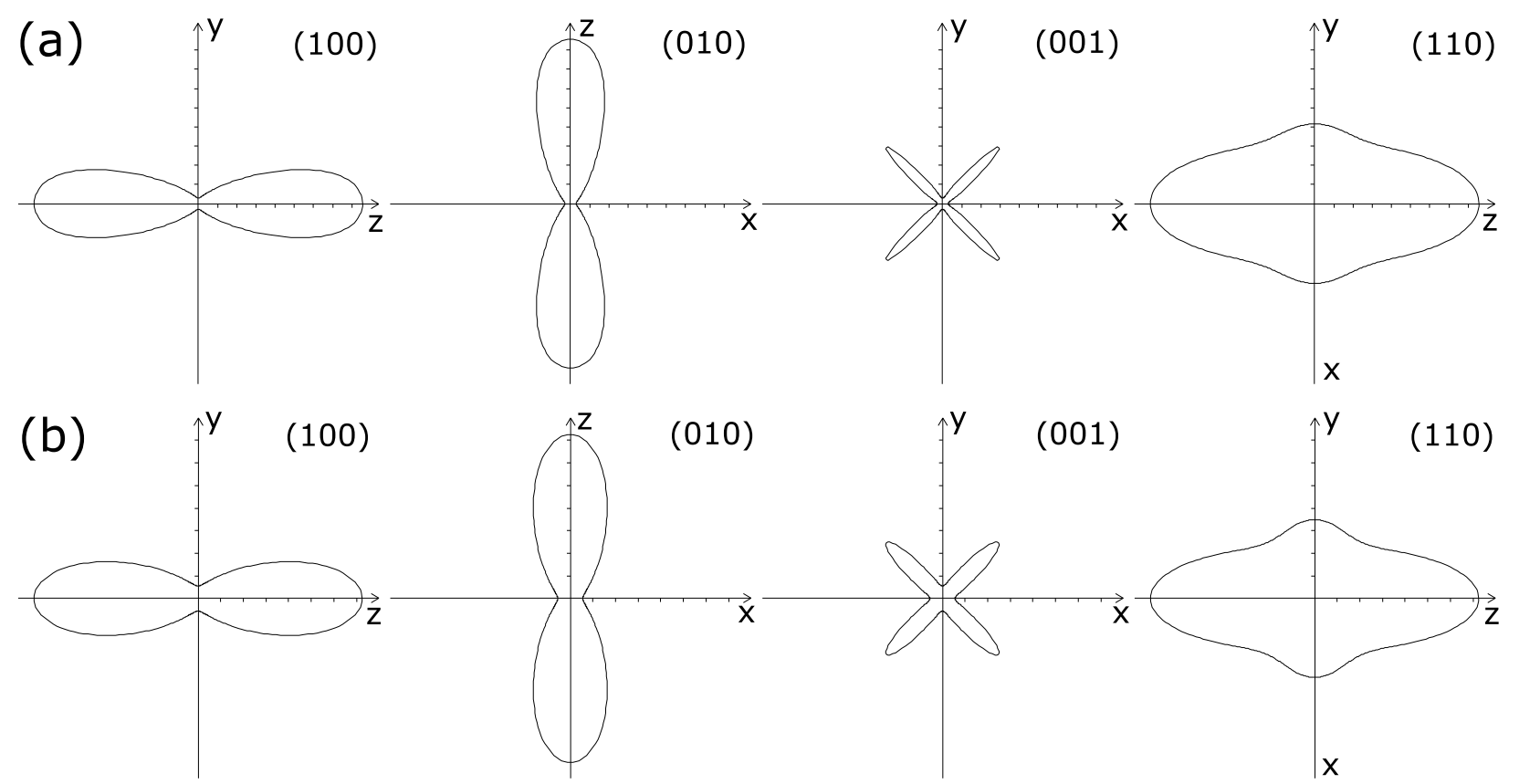

Figure S19. Cartesian projections of the elastic tensor of (a) NOTT-400 (EXEQII), and (b) CPF-1 (HAFVUH). 


\section{MIL-60, MIL-116, MIL-118, and MIL-122}

The frameworks of the mog underlying topology are the stiffest of the MOFs under consideration that is seen from their average (by Voigt) Young's modulus in the range 68-95 GPa (Table S8). Indeed, this is caused by a 4-topic nature of the ligands and the lowest porosity $(13-28 \%)$.

In three MOFs, MIL-118(Al), MIL-116(Al), and MIL-60(V), the tensor of the Young's modulus has six maxima: two along the rod direction (010) and four along the connections of the rods with ligands in the plane orthogonal to the rods (Fig. S20, Table S13). The (010) projection is of a butterfly-like shape with the deepest minimum along $a$, and less deep along $c$. The space symmetry of the structure also affects the point symmetry of the elastic tensor. The orthorhombic symmetry of MIL-118(Al) results in a mirror symmetry of the tensor in the $y z, x z$, and $x y$ planes, as well as in coincidence of Cartesian axis of tensor with the unit cell vectors. Four maxima of the Young's modulus along [101], [10-1], [-101], [-10-1] in the plane orthogonal to the rods are equivalent $(134.3 \mathrm{GPa})$, and four minima differ along $a(14.8 \mathrm{GPa})$ and $c(110.7 \mathrm{GPa})$. The tensor of triclinic MIL-60(V) lacks this symmetry (Fig. S20); it has only an inversion center, and the Cartesian axes $x$ and $y$ of the tensor do not coincide with the unit cell vectors $a$ and $b$. The tensor has two maxima in the plane orthogonal to rods, 108.1 and $116.8 \mathrm{GPa}$, and two minima, 69.5 and $72.0 \mathrm{GPa}$.

The maxima of the Young's modulus for MIL-118(Al) (107.9 GPa) and MIL-60(V) (73.1 GPa) along the rods are less pronounced than along rod connections to ligands in the orthogonal projection.

The MIL-116(Al) has the Young's modulus along rods almost the same as MIL(118), but the projections of both maxima and minima orthogonal to rods are much stiffer. Indeed, the two additional free carboxylic groups of the linker in MIL-116(Al) are responsible for reinforcing the framework due to decreasing the porosity. 

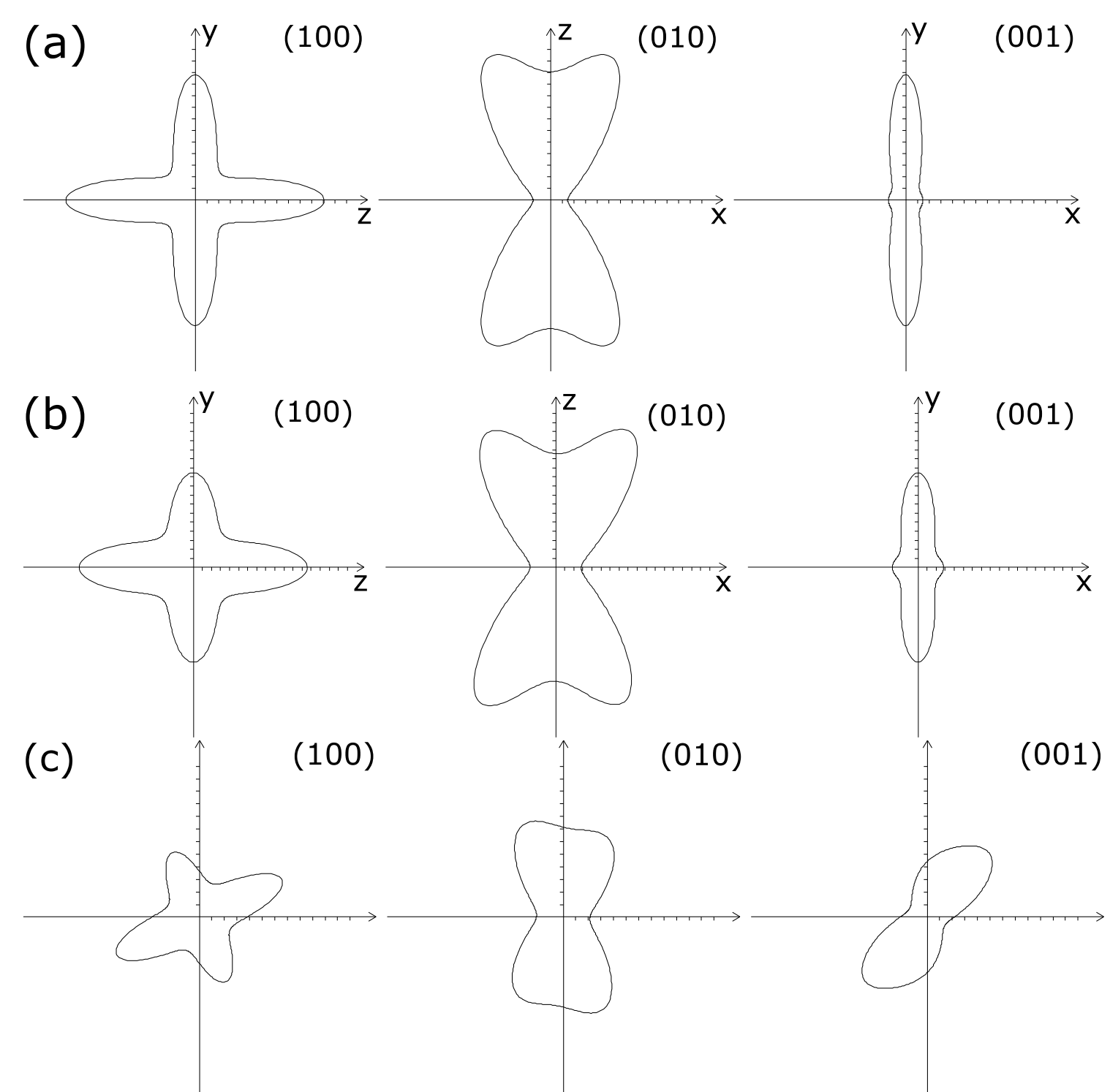

Figure S20. Cartesian projections of the elastic tensor of (a) MIL-118 (GUKVEO), (b) MIL-116 (XOCROY), (c) MIL-60 (GUXQAR).

Unexpectedly, in the remaining two frameworks, the tensors have only two sharp peaks (Fig. S21, Table S13). One is along the $z$ axis, $107 \mathrm{GPa}$ for MIL-122(Al) and $81 \mathrm{GPa}$ for MIL122(Ga). The second peak demonstrate twice as high stiffness along $a$ axis: $210 \mathrm{GPa}$ in MIL122(Al) and $180 \mathrm{GPa}$ in MIL-122(Ga). Such a significant increase of the stiffness is likely because of a larger aspect ratio (1.9) of the rectangular 1,4,5,8-naphthalenetetracarboxylate ligand in comparison to the benzene-1,2,4,5-tetracarboxylate ligand (1.7), which results in merging the two maxima in diagonal directions into one along the $a$ axis, which corresponds to the wide aperture of the ligand. 


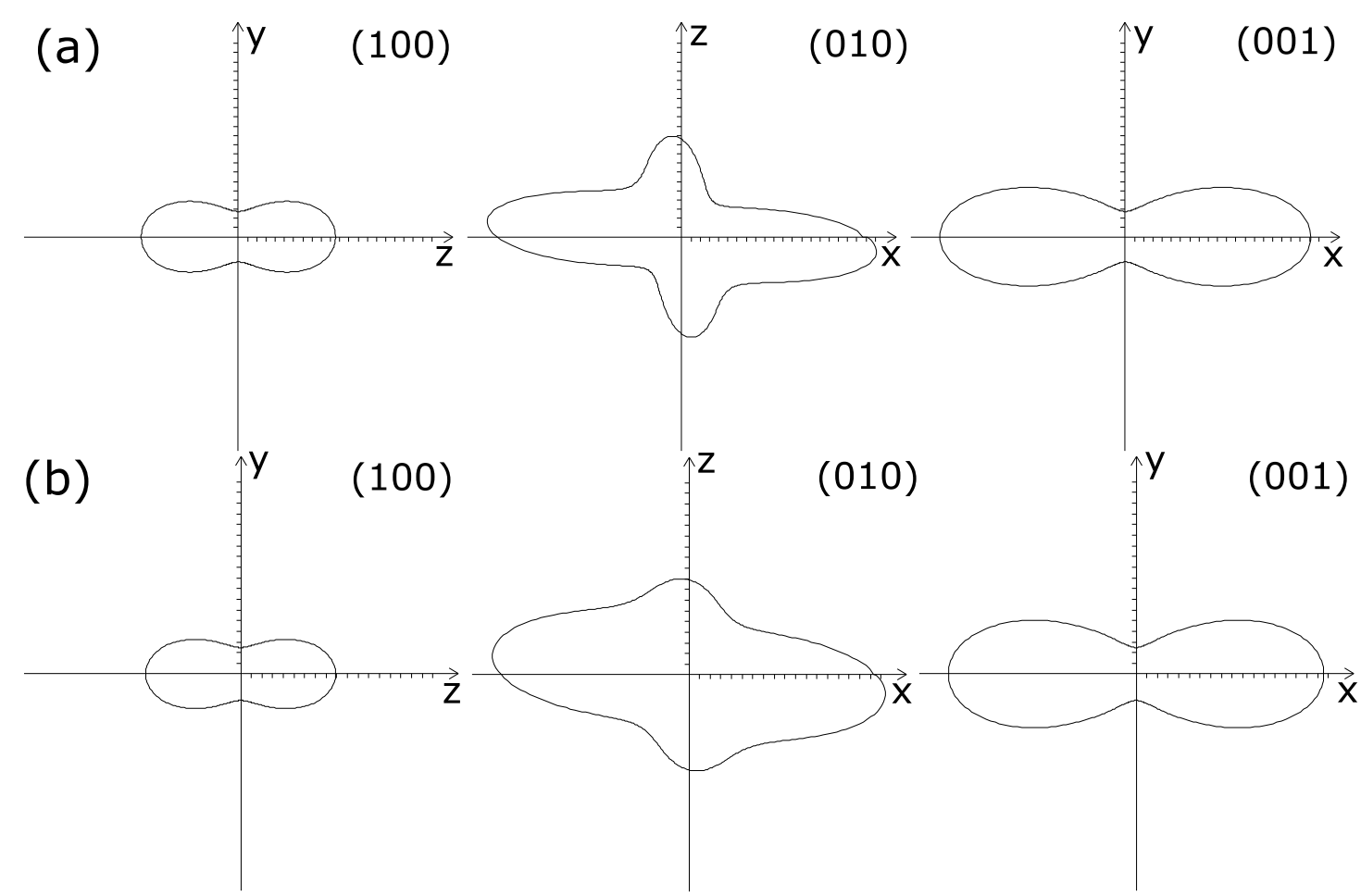

Figure 21. Cartesian projections of the elastic tensor projections for (a) MIL-122(Al) (NUFYAP) and (b) MIL-122(Ga) (NUFYET).

Table S13. Young's modulus (GPa) along specific directions for MIL-60(V), MIL-118(Al), MIL-116(Al), MIL-122(Al), and MIL-122(Ga).

\begin{tabular}{|l|l|l|l|l|l|}
\hline Structural species along & MIL-60(V) & MIL-116(Al) & MIL-118(Al) & MIL-122(Al) & MIL-122(Ga) \\
\hline Rpecific direction & & & & & \\
\hline Diagonals of linker & 73.1 & 104.3 & 107.9 & 109.8 & 90.4 \\
\hline Narrow aperture of ligand & 69.5 & 26.9 & 14.8 & 27.4 & - \\
\hline Wide aperture of ligand & 72.0 & 150.4 & 110.7 & 212.0 & 184.8 \\
\hline
\end{tabular}

\section{References}

(1) Loiseau, T.; Serre, C.; Huguenard, C.; Fink, G.; Taulelle, F.; Henry, M.; Bataille, T.; Ferey, G. A Rationale for the Large Breathing of the Porous Aluminum Terephthalate (MIL-53) Upon Hydration. Chem.-Eur. J. 2004, 10, 1373-1382.

(2) Devic, T.; Horcajada, P.; Serre, C.; Salles, F.; Maurin, G.; Moulin, B.; Heurtaux, D.; Clet, G.; Vimont, A.; Greneche, J.-M.; Le Ouay, B.; Moreau, F.; Magnier, E.; Filinchuk, Y.; Marrot, J.; Lavalley, J.-C.; Daturi, M.; Ferey, G.Functionalization in Flexible Porous Solids: Effects on the Pore Opening and the Host-Guest Interactions. J. Am. Chem. Soc. 2010, 132, 1127-1136. 
(3) Volkringer, C.; Loiseau, T.; Guillou, N.; Ferey, G.; Elkaim, E.; Vimont, A. XRD and IR structural investigations of a particular breathing effect in the MOF-type gallium terephthalate MIL-53(Ga). Dalton Trans., 2009, 2241-2249.

(4) Barthelet, K.; Marrot, J.; Riou, D.; Ferey, G.A Breathing Hybrid Organic-Inorganic Solid with Very Large Pores and High Magnetic Characteristics. Angew. Chem., Int. Ed. 2002, 41, 281-284.

(5) Zhang, X. X.; Chui, S. Y.; Williams, I. D. Cooperative magnetic behavior in the coordination polymers $\left[\mathrm{Cu}_{3}(\mathrm{TMA})_{2} \mathrm{~L}_{3}\right]\left(\mathrm{L}=\mathrm{H}_{2} \mathrm{O}\right.$, pyridine). J. Appl. Phys. 2000, 87, 6007-6009

(6) Whitfield, T. R.; Wang, X.; Jacobson, A. J. Hydrothermal Synthesis of a Microporous Organic-Inorganic Hybrid Framework $\left[\mathrm{Fe}_{0.28} \mathrm{~V}_{0.72} \mathrm{OH}_{0.8}\left(\mathrm{NH}_{4}\right)_{0.2}\left(\mathrm{C}_{8} \mathrm{H}_{4} \mathrm{O}_{4}\right)\right] 0.53\left(\mathrm{C}_{8} \mathrm{H}_{4} \mathrm{O}_{4}\right)$. Mat. Res. Soc. Symp. Proc. 2003, 755, 191-196. (Whitfield, T.R.; Wang, X.; Jacobson, A.J. CCDC 233273: Experimental Crystal Structure Determination, 2014, DOI: $10.5517 /$ cc7tqyp)

(7) Volkringer, C.; Loiseau, T.; Guillou, N.; Ferey, G.; Haouas, M.; Taulelle, F.; Elkaim, E.; Stock N. High-Throughput Aided Synthesis of the Porous Metal-Organic Framework-Type Aluminum Pyromellitate, MIL-121, with Extra Carboxylic Acid Functionalization. Inorg. Chem. 2010, 49, 9852-9862.

(8) Barthelet, K.; Riou, D.; Nogues, M.; Ferey, G. Synthesis, Structure, and Magnetic Properties of Two New Vanadocarboxylates with Three-Dimensional Hybrid Frameworks. Inorg. Chem. 2003, 42, 1739-1743.

(9) Fateeva, A.; Horcajada, P.; Devic, T.; Serre, C.; Marrot, J.; Grenèche, J.-M.; Morcrette, M.; Tarascon, J.-M.; Maurin, G.; Férey G. Synthesis, Structure, Characterization, and Redox Properties of the Porous MIL-68(Fe) Solid. Eur. J. Inorg. Chem. 2010, 3789-3794.

(10) Barthelet, K.; Marrot, J.; Férey, G.; Riou, D. V ${ }^{\mathrm{III}}(\mathrm{OH})\left\{\mathrm{O}_{2} \mathrm{C}-\mathrm{C}_{6} \mathrm{H}_{4}-\mathrm{CO}_{2}\right\} \cdot\left(\mathrm{HO}_{2} \mathrm{C}-\mathrm{C}_{6} \mathrm{H}_{4}-\right.$ $\left.\mathrm{CO}_{2} \mathrm{H}\right)_{\mathrm{x}}(\mathrm{DMF})_{\mathrm{y}}\left(\mathrm{H}_{2} \mathrm{O}\right)_{\mathrm{z}}$ (or MIL-68), a new vanadocarboxylate with a large pore hybrid topology: reticular synthesis with infinite inorganic building blocks? Chem. Commun., 2004, 520-521.

(11) Volkringer, C.; Meddouri, M.; Loiseau, Th.; Guillou, N.; Marrot, J.; Ferey, G.; Haouas, M.; Taulelle, F.; Audebrand, N.; Latroche, M. The Kagome Topology of the Gallium and Indium Metal-Organic Framework Types with a MIL-68 Structure: Synthesis, XRD, Solid-State NMR Characterizations, and Hydrogen Adsorption. Inorg. Chem. 2008, 47, 11892-11901.

(12) Canivet, J.; Bonnefoy, J.; Daniel, C.; Legrand, A.; Coasne, B.; Farrusseng D. Structureproperty relationships of water adsorption in metal-organic frameworks. New J. Chem. 2014, 38, 3102-3111.

(13) Pera-Titus, M.; Savonnet, M.; Farrusseng, D. Evaluation of Energy Heterogeneity in Metal-Organic Frameworks: Absence of Henry's Region in MIL-53 and MIL-68 Materials? J. Phys. Chem. C 2010, 114, 17665-17674.

(14) Comotti, A.; Bracco, S.; Sozzani, P.; Horike, S.; Matsuda, R.; Chen, J.; Takata, M.; Kubota, Y.; Kitagawa, S. Nanochannels of Two Distinct Cross-Sections in a Porous Al-Based Coordination Polymer. J. Am. Chem. Soc. 2008, 130, 13664-13672.

(15) Reinsch, H.; van der Veen, M. A.; Gil, B.; Marszalek, B.; Verbiest, T.; De Vos, D. E.; Stock, N. Structures, sorption characteristics and nonlinear optical properties of a new series of highly stable aluminium MOFs. Chem. Mat. 2013, 25, 17-26. 
(16) Reinsch, H.; Waitschat, S.; Stock, N. Mixed-linker MOFs with CAU-10 structure: synthesis and gas sorption characteristics. Dalton Trans. 2013, 42, 4840-4847.

(17) Frohlich, D.; Pantatosaki, E.; Kolokathis, P. D.; Markey, K.; Reinsch, H.; Baumgartner, M.; van der Veen, M. A.; De Vos, D. E.; Stock, N.; Papadopoulos, G. K.; Henninger, S. K.; Janiak C. Water adsorption behaviour of CAU-10-H: a thorough investigation of its structureproperty relationships. J. Mater. Chem. A 2016, 4, 11859-11869.

(18) Ibarra, I. A.; Yang, S.; Lin, X.; Blake, A. J.; Rizkallah, P. J.; Nowell, H.; Allan, D. R.; Champness, N. R.; Hubbersteya, P.; Schroder, M. Highly porous and robust scandium-based metal-organic frameworks for hydrogen storage. Chem. Commun. 2011, 47, 8304-8306.

(19) Reinsch, H.; Krüger, M.; Marrot, J.; Stock, N. First Keto-Functionalized Microporous AlBased Metal-Organic Framework: $\left[\mathrm{Al}(\mathrm{OH})\left(\mathrm{O}_{2} \mathrm{C}-\mathrm{C}_{6} \mathrm{H}_{4}-\mathrm{CO}-\mathrm{C}_{6} \mathrm{H}_{4}-\mathrm{CO}_{2}\right)\right]$. Inorg. Chem. 2013, $52,1854-1859$.

(20) Jin, Z.; Zhao, H.-Y.; Zhao, X.-J.; Fang, Q.-R.; Long, J. R.; Zhu, G.-S. A novel microporous MOF with the capability of selective adsorption of xylenes. Chem. Commun. 2010, $46,8612-8614$.

(21) Tan, Y.-X.; Wang, F.; Kang, Y.; Zhang, J. Dynamic microporous indium(III)-4,4'oxybis(benzoate) framework with high selectivity for the adsorption of $\mathrm{CO}_{2}$ over $\mathrm{N}_{2}$. Chem. Commun. 2011, 47, 770-772.

(22) Lin, Q.; Wu, T.; Zheng, S.-T.; Bu, X.; Feng. P. A chiral tetragonal magnesiumcarboxylate framework with nanotubular channels Chem. Commun. 2011, 47, 11852-11854.

(23) Volkringer, C.; Loiseau, T.; Guillou, N.; Ferey, G.; Haouas, M.; Taulelle, F.; Audebrand, N.; Margiolaki, I.; Popov, D.; Burghammer, M.; Riekel, C. Structural Transitions and Flexibility during Dehydration-Rehydration Process in the MOF-type Aluminum Pyromellitate $\mathrm{Al}_{2}(\mathrm{OH})_{2}\left[\mathrm{C}_{10} \mathrm{O}_{8} \mathrm{H}_{2}\right]$ (MIL-118). Cryst. Growth Des. 2009, 9, 2927-2936.

(24) Barthelet, K.; Riou, D.; Nogues, M.; Ferey, G. Synthesis, Structure, and Magnetic Properties of Two New Vanadocarboxylates with Three-Dimensional Hybrid Frameworks. Inorg. Chem. 2003, 42, 1739-1743.

(25) Volkringer, C.; Loiseau, T.; Guillou, N.; Férey, G.; Popov, D.; Burghammer, M.; Riekel, C. Synthesis and structural characterization of metaleorganic frameworks with the mellitate linker $\mathrm{M}_{2}(\mathrm{OH})_{2}\left[\mathrm{C}_{12} \mathrm{O}_{12} \mathrm{H}_{2}\right] \cdot 2 \mathrm{H}_{2} \mathrm{O}(\mathrm{M}=\mathrm{Al}, \mathrm{Ga}, \mathrm{In}) \mathrm{MIL}-116$. Solid State Sci. 2013, 26, 38-44.

(26) Volkringer, C.; Loiseau, T.; Guillou, N.; Férey, G.; Elkaïm, E. Syntheses and structures of the MOF-type series of metal 1,4,5,8,-naphthalenetetracarboxylates $\mathrm{M}_{2}(\mathrm{OH})_{2}\left[\mathrm{C}_{14} \mathrm{O}_{8} \mathrm{H}_{4}\right](\mathrm{Al}$, $\mathrm{Ga}, \mathrm{In}$ ) with infinite trans-connected M-OH-M chains (MIL-122). Solid State Sci. 2009, 11, $1507-1512$. 